\title{
Does health insurance improve health for all? Heterogeneous effects on children in Ghana
}

\author{
Lisa Bagnoli *
}

July, 2019

\begin{abstract}
This paper assesses whether health insurance is successful in improving health. More specifically, it investigates whether a same health insurance scheme has differentiated impacts on children depending on the way it is implemented and on the characteristics of the beneficiaries. To do so, I analyze the case of Ghana's National Health Insurance Scheme that provides free coverage for children and has decentralized operations. I exploit the Multiple Indicator Cluster Survey of 2011 and I use propensity score matching to account for selection in the scheme. The study finds that, even though the NHIS is successful in improving health outcomes among insured children in Ghana, gains are not shared equally across regions. To understand this regional heterogeneity, mechanisms are investigated. The positive impact of health insurance is concentrated among the lower-income households in regions with a high quality of public health care. Further evidence points to the importance of health care utilization to explain these results. This paper sheds a new light on the mixed results of the literature on the impact of health insurance on health outcomes. It provides an understanding of the sources of the heterogeneous impact of a National Health Insurance Scheme and highlights the importance of context and implementation as drivers of its effectiveness. Such evidence is relevant for both the evaluation and monitoring of existing health care schemes and for the implementation of new large-scale public policies.
\end{abstract}

Keywords: Health insurance; Health; Children; Heterogeneity; Africa; Ghana

I am grateful to Gani Aldashev, Antonio Estache, two anonymous referees, Arun Agrawal (the editor) and participants to the N.G.O. workshop in Stockholm and to the ECARES seminar for useful suggestions and discussions. I also thank the Ghana Statistical Office for the release of the MICS 2011 GPS coordinates.

* ECARES - Université libre de Bruxelles - F.R.S.-FNRS Aspirant.

50, Av. F.D. Roosevelt, CP 139, B-1050 Brussels, Belgium.

Lisa.Bagnoli@ulb.ac.be 


\section{Introduction}

Since the mid-2000s, the adoption of health insurance schemes for developing countries has replaced the enthusiasm of the late 1980s for health care financed through user fees, initially widely promoted in the literature (Akin, Birdsall, \& de Ferranti, 1987; Gilson \& McIntyre, 2005; Yates, 2009; World Health Organization, 2010). The insurance approach was expected to reduce the financial stress associated with user fees and to improve access to health care (Nyman, 1999). These payoffs were likely to apply particularly strongly to lower-income households, who tend to be more responsive to changes in the price of health care than wealthier households (e.g. Gertler, Locay, \& Sanderson, 1987; Xu et al., 2006; Hangoma, Robberstad, \& Aakvik, 2018).

The benefits of health insurance schemes on health care utilization and household financial protection have been widely documented (e.g: Giedion \& Diaz, 2010; Jütting, 2004; Trujillo, Portillo, \& Vernon, 2005; Wagstaff, 2007; Spaan et al., 2012; Gruber, Hendren, \& Townsend, 2014). Evidence on the effectiveness of these insurance schemes on health outcomes is however mixed. For example, health insurance has been found to improve health in India (Aggarwal, 2010), Mexico (Pfutze, 2014), the Philippines (Quimbo, Peabody, Shimkhada, Florentino, \& Solon, 2011) or Taiwan (Lee et al., 2010), but not in China (Lei \& Lin, 2009; Chen \& Jin, 2012) or Costa Rica (Dow \& Schmeer, 2003). The literature has not yet offered a clear analytical explanation for these contrasting results. Understanding the source of the heterogeneous impact of health insurance on health is the aim of this paper, illustrated in the context of the adoption of a national health insurance scheme in Ghana.

The approach builds on suggestions made by various researchers trying to explain failures of health insurance in very different settings. They point to the need of paying greater attention to the contexts and to the details of the implementation strategy adopted by the authorities (Ridde \& Morestin, 2011). For example, Fink, Robyn, Sié, and Sauerborn (2013) explain the increase in mortality rates among the elderly resulting from the introduction of health insurance in Burkina Faso by adverse incentives for the medical staff. Likewise, Barros (2008) attributes the negligible impact on health outcomes of a large insurance scheme in Mexico to the poor quality of care. In contrast, Miller, Pinto, and Vera-Hernández (2009) credit the positive impact of an insurance scheme in Colombia to the strength of incentives for health care providers. And Mate et al. (2013) claim that the adequate quality of health care is a necessary condition for health insurance to be able to impact health outcomes. 
These recognitions of the potential role of the context, scheme design and implementation characteristics for the success of health insurance policies are important insights but they have not yet been tested formally. The main contribution of this paper is to provide evidence on these factors as drivers of health insurance effectiveness. The analysis focuses on two dimensions: the characteristics of the beneficiaries and the conditions of implementation. It investigates whether a same national health insurance scheme has differentiated impacts on child health in Ghana. The data allow explicit control of the wealth of the recipients' household and for the differences in the quality of public health care across regions.

Ghana provides an appropriate context for investigating this question. In 2003, it introduced the National Health Insurance Scheme (NHIS). A national legislation and regulation set up the scheme and its operations are decentralized at regional and district levels. Children do not need to pay an annual premium to become insured, but they do need to register at the closest district office. Nonetheless, in 2011, about half of the children under five years old were not covered by the NHIS. This context of imperfect take-up and decentralized operations offers the opportunity to test whether the impact of the scheme depends on the characteristics of the beneficiaries and on the local implementation of the program.

So far, research has demonstrated that the NHIS reduces household health care expenditures (Aryeetey et al., 2016; Nguyen, Rajkotia, \& Wang, 2011; Okoroh et al., 2018; Strupat \& Klohn, 2018). There is somewhat less consensus on the impact of the NHIS on health care utilization. The majority of studies suggests that health insurance leads to an increase in the use of health care (Mensah, Oppong, \& Schmidt, 2010; Brugiavini \& Pace, 2016; Bosomprah, Ragno, Gros, \& Banskota, 2015; Dzakpasu et al., 2012; Browne et al., 2016). However, other studies reveal that the NHIS has a positive impact on the frequency of maternal health care utilization but not on the timing of the crucial first antenatal care visit (Dixon, Tenkorang, Luginaah, Kuuire, \& Boateng, 2014) or a positive impact on facility delivery but not on antenatal care utilization (Singh et al., 2015).

Results are even more mixed with regard to the effects of the NHIS on health outcomes. Most studies concentrate on specific geographical areas. In the Northern region, the NHIS leads to a decrease in the number of days of illness and better self-reported health outcomes (Asuming, 2013). Similarly, in the Brong Ahafo and the Upper East regions, the NHIS decreases birth complications as well as infant and maternal mortality (Mensah et al., 2010). On the other hand, in the Greater Accra region, even though health care utilization increases, there is no significant effect on a variety of health 
outcomes among children (Ansah et al., 2009). Bosomprah et al. (2015) use nationally representative data and reveal that, even though health care utilization increases, the NHIS has no impact on underfive mortality. However, the authors do not examine whether these national averages hide local heterogeneities. This paper reconciles these mixed findings by looking beyond national averages and investigating the predictors of this heterogeneity.

To do so, I exploit the detailed Multiple Indicator Cluster Survey of 2011, a large household survey representative at the national and regional levels. A particular feature of this survey is that blood tests were conducted during the interviews. I therefore investigate the impact of the NHIS on both height-for-age and anemia as health proxies among children under five years old. An additional contribution of this paper is thus its specific focus on children and in particular the impact of a largescale insurance program on more intermediate outcomes than child mortality. In Ghana, anemia was the second leading cause of deaths and hospital admissions for children under five years old in 2011 . $^{1}$ So far, few studies have focused on this outcome. Insurance membership is associated with lower odds of developing anemia in Ghana (Dwumoh, Essuman, \& Afagbedzi, 2014) but in Greater Accra specifically, only the anemia of the sickest children was affected by the removal of user fees (PowellJackson, Hanson, Whitty, \& Ansah, 2014).

I use propensity score matching to address the concern that the same factors can drive both insurance membership and health outcomes. I first estimate the probability of enrollment into health insurance among children under five years old, accounting for many factors that can predict insurance membership. Second, I assess the impact of the NHIS on children's health. Third, I investigate whether this scheme presents heterogeneities in its impact. In particular, I conduct the analysis at the regional level, across income groups and across areas with different quality of public health care. As an extension, I investigate the impact of the NHIS on health care utilization to understand the pathway between insurance membership and health outcomes. If health insurance does not improve the health of insured children, this may be caused by health insurance not increasing the use of health care, or by the care provided not having an effect on health outcomes (Levy \& Meltzer, 2001).

The results of the paper are first that, on average, the NHIS improves health outcomes among insured children in Ghana. Insured children have a height-for-age 0.17 standard deviations closer to

${ }^{1}$ Ghana Health Facts and Figures - 2011 : https://www.ghanahealthservice.org/ghs-itemdetails.php? cid $=5 \&$ scid $=55 \&$ iid $=130$ 
the reference than non-insured. They also have a $20 \%$ lower probability of having anemia. Both these effects are significant at the $1 \%$ level. However, those gains are not shared equally across regions. Four out of the ten administrative regions do not present any significant health improvement attributable to the insurance scheme. These regional results reconcile the previous literature that focused on specific areas in Ghana (Asuming, 2013; Mensah et al., 2010; Ansah et al., 2009). Both household wealth and the quality of health care are key factors explaining this heterogeneity. Health improvements attributable to the NHIS are indeed concentrated among lower-income households living in regions with a high quality of public health care.

Finally, the NHIS increases overall health care utilization. However, these effects are again heterogeneous. In regions where the quality of care is low, the NHIS increases the use of health care facility (HCF) but this does not translate into better health. In contrast, in regions with a higher quality of care, the NHIS increases the use of HCF and induces a shift toward the use of HCF compared to other sources of treatment. This does translate into health gains for insured children. With respect to wealth, insured children in the lower-income group have a higher probability of receiving higher-level procedures than non-insured children, while there is no significant difference among children in the higher-income group. These results are in line with the heterogeneous effects of the NHIS on health outcomes depending on wealth. They suggest that the NHIS removes a financial constraint for lowerincome households, which translates into improved health among insured children.

The remainder of the paper is structured as follows. Section 2 presents background information on Ghana's NHIS. The data are described in section 3 and the methodology in section 4. Section 5 presents the results of the analysis and section 6 concludes.

\section{Ghana's National Health Insurance Scheme}

In 1957 at the time of independence, Ghana had the highest income per capita in West Africa, basing its prosperity on agricultural exports. It introduced tax-funded free medical services for all. In the 1980s, as the cocoa prices fell, the Government implemented a severe Structural Adjustment Program sponsored by the World Bank and the IMF. Among others, it required the elimination of subsidies on social services. The so-called cash-and-carry system started as user fees were set on health care services. This caused a collapse in health indicators and a drop of at least 25\% in usage, mainly among the poor, the elderly, women and rural residents (Mensah et al., 2010; Dixon, 2011). This 
inability to help the most vulnerable caused a wide discontent about the system leading to an increasing pressure to replace it.

In 2003, the National Health Insurance Act established the NHIS that became fully operational in 2005. Its stated mission is "to assure equitable universal access for all residents of Ghana to an acceptable quality of essential health services without out-of-pocket payment being required at the point of service use" (Ministry of Health, 2004). The scheme is regulated by the National Health Insurance Authority and the operations are decentralized at the regional and district levels.

The NHIS allows for the existence of different insurance plans: district mutual health insurance schemes, private mutual (or community-based) insurance schemes and private commercial insurance schemes. The district mutual health insurance schemes are the most common as they cover more than 99\% of the insured population (Gajate-Garrido \& Owusua, 2013). This type of scheme is the only one to receive subsidies from the National Health Insurance Fund. In the remainder of the paper, children referred to as being insured with the NHIS are actually only those covered by district mutual health insurance. The legislation imposes that everyone in the country should be covered by a health insurance. In practice, this rule is not enforced: in 2011, 69\% of women, $56 \%$ of men and $54 \%$ of children are insured with the NHIS (Ghana Statistical Service, 2011).

To become a member of the NHIS, individuals have to pay an annual premium. Children under 18 years old are nevertheless exempted from premium payment, as are maternal services. ${ }^{2}$ Even though children are not subject to the annual premium, they do need to have their insurance card in order to be covered. This implies a processing fee, a registration in a district office, located in every district capital, and a yearly renewal of the membership. Children under three months old can however be treated using their mother's NHIS card.

NHIS members are only covered in facilities that are accredited by the National Health Insurance Authority, although these include public and private facilities. ${ }^{3}$ Patients who are not covered by a health insurance must pay for their treatment out of pocket, but they can be treated in any facility

${ }^{2}$ Children are exempted from the premium payment since 2009 . Before that year, children could be enrolled for free only if their parents were members of the NHIS.

${ }^{3}$ In 2010 , the total number of accredited facilities was 2,647, of which $55 \%$ are owned by the government, $39 \%$ are privately owned and the others are either mission or quasi-governmental facilities (National Health Insurance Authority, 2010). 
(Dixon, Tenkorang, \& Luginaah, 2013). NHIS members are covered for a comprehensive list of services and medications. This list, which includes about $95 \%$ of common health services in Ghana, covers general out patient and in patient services, oral health, eye care, maternity care and emergencies. The NHIS therefore reduces financial barriers to health care since members should not have to make any direct payment when using covered services or when purchasing covered medications.

In practice however, there remain important issues concerning the implementation of the NHIS. For example, Durairaj, D'Almeida, and Kirigia (2010) report that still around 40\% of insured patients make informal payments to receive care. Other studies highlight challenges faced by the NHIS, such as the low monitoring of providers, inadequate technical capacity, delays in the reimbursement of services, incorrect applications of the tariffs, incentives to over-provide or the lack of awareness about the covered drugs list (Durairaj et al., 2010; Gajate-Garrido \& Owusua, 2013; Alhassan, NketiahAmponsah, \& Arhinful, 2016). Beneficiaries also perceive these limitations. Duku, NketiahAmponsah, Janssens, and Pradhan (2018) show that the perception of health care quality is significantly lower among members of the NHIS compared to non-members. However, quality concerns do not only affect NHIS members. Although the quality of medical practice in Ghana is considered to be high on average, there indeed remain important issues. Media frequently report that the staff in some hospitals are accused of unprofessional acts, reporting favoritism in the priority of care and time spent with patients. Other challenges include inadequate infrastructures and shortage of doctors (Gajate-Garrido \& Owusua, 2013; Drislane, Akpalu, \& Wegdam, 2014). Since there is evidence of quality issues in Ghana and that the operations of the NHIS are decentralized, it is plausible that the quality of public care in Ghana is heterogeneous across regions. For example, Andoh-Adjei, Nsiah-Boateng, Asante, Spaan, and van der Velden (2018) highlight the existence of regional heterogeneity in the perception of the quality of care.

\section{Data and descriptive statistics}

\subsection{Data sources}

The main data used in this paper come from the Multiple Indicator Cluster Survey (MICS) conducted in 2011 in Ghana. It is a large household survey developed by the UNICEF and focused mainly on issues related to women and children. While it is the fourth wave of this survey, it is the first one to include information on health insurance membership. Moreover, the timing of this survey 
provides a sufficient time gap, six years, since the introduction of the NHIS to analyze its impact. A fifth wave was conducted in 2017-2018, but the data are not yet available as of this date. In addition, this survey includes rapid diagnostic blood tests during the interviews for children, which offers information on anemia prevalence. The MICS dataset also provides wealth quintiles for each household. They are computed according to an asset-based wealth index such as the wealth index used in Demographic and Health Surveys. This survey is representative at the national level, at the ten administrative regions, and at urban and rural areas within each of these regions. The final sample includes 7,092 children under five years old.

The MICS dataset also includes the geographic location of households. Therefore, I used the location of all health facilities in the country to construct the distance to the closest health care facility. ${ }^{4}$ I complement this information with the distance to the nearest district capital, where the NHIS district offices are located. Finally, I use information from the Afrobarometer round 5 survey conducted in Ghana in 2012 to have a measure of public health care quality. I construct this measure for each administrative region. The variable refers to the percentage of respondents within each region who answered "very badly" to the question "How would you say the current government is handling: Improving basic health services" on a 4-item scale. This measure is a perceived measure of public health care quality. This is a desirable feature in this context, as it likely drives trust and the use of health care services. Moreover, given the large variety of challenges faced by the health sector in Ghana (see section 2), it might provide a more comprehensive view of health care quality than a specific measure of facilities' characteristics.

\subsection{Variables}

\subsubsection{Health insurance}

The key dependent variable is whether the child is covered with health insurance. It is a dummy variable equal to one if the child is covered by the NHIS and zero if the child has no insurance at all. ${ }^{5}$

${ }^{4}$ Health facilities, Ghana Open Data Initiative, https://data.gov.gh/dataset/health-facilities

${ }^{5}$ In the sample, 32 children $(0.45 \%$ of the total sample) are covered by another type of health insurance (community based or privately owned). Because of the small sample size, these children are not included in the analysis. 


\subsubsection{Measures of health outcomes}

The height-for-age z-score (HAZ) is a commonly used anthropometric measure of cumulative health of a child. It evaluates linear growth and can reveal stunting, caused by long-term malnutrition and recurrent or chronic illness. The sample includes 6,952 children with a valid measure of HAZ. ${ }^{6}$ The variable is calculated in z-scores: the distance in standard deviations from the median of the reference population. On top of HAZ, anemia results of the blood tests measure another important dimension of health (World Health Organization [WHO], 2011). Anemia in children can impair their mental, physical and social development (Ewusie, Ahiadeke, Beyene, \& Hamid, 2014). Anemia is caused by iron deficiency, other nutritional deficiencies or other health disorders such as inflammation or infection. It reflects an insufficient number of red blood cells to meet the body's physiologic needs. Blood tests were only conducted on children over six months of age. The final sample includes 4,223 children with anemia results. ${ }^{7}$ The variable is equal to one if the child is not anemic and zero otherwise. ${ }^{8}$

\subsection{Descriptive statistics}

\subsubsection{Health insurance}

Even though health insurance is free for children, only 54\% of them are insured. As illustrated in Figure 1, this varies across regions from $36.7 \%$ in the Central region to $69.5 \%$ in the Upper West region. There is a negative correlation between the insurance coverage of a region and its wealth. Indeed, the northern regions (mainly the Upper West and East regions) are the poorest and most insured ones while the Greater Accra region is the wealthiest one and presents a very low coverage rate among children under five years old. One possible explanation for this fact might be that wealthier regions have a higher variety of sources of treatment and that these are different to those in the poorest regions.

${ }^{6}$ This corresponds to over $98 \%$ of the total sample. Children do not have a valid measure of HAZ if their full birth date is unknown, if the height was not measured, for example if the child was absent, or if the measurement was out of the plausible range.

${ }^{7}$ Among the eligible children, the response rate was over $98 \%$ and was similar across wealth quintiles.

${ }^{8} \mathrm{~A}$ child is considered as not anemic if he or she has more than 100 grams of hemoglobin per liter of blood. This corresponds to the threshold of moderate anemia for children under five years old (WHO, 2011). 
For example, the private health sector might be more developed in a region such as Greater Accra, which would decrease the incentives of seeking care through the NHIS.

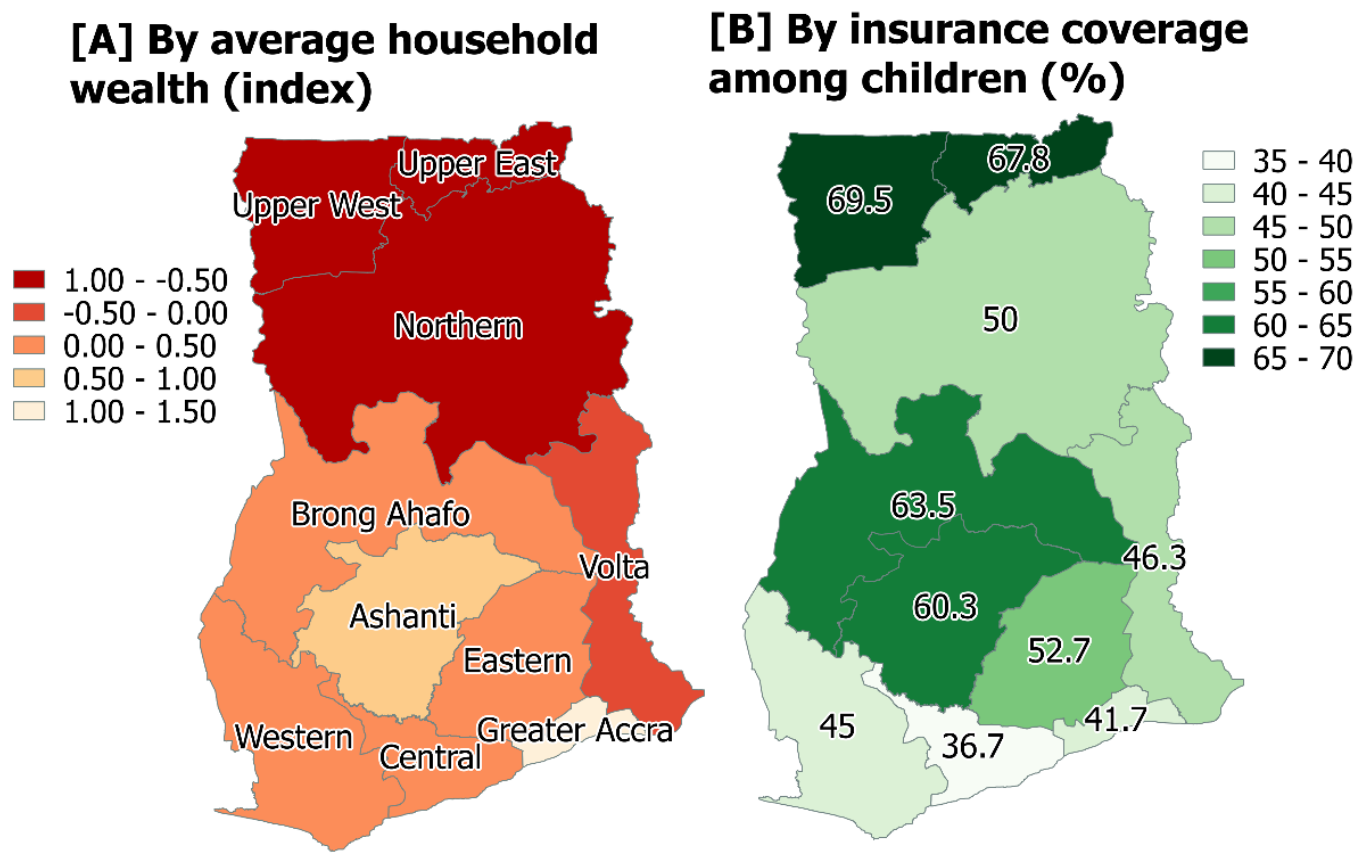

[A] Average wealth index (asset-based) of households within the region (MICS, 2011)

[B] Percentage of children under five years old covered by the NHIS (MICS, 2011)

Figure 1: Map of Ghana

\subsubsection{Health outcomes}

Table 1 summarizes the descriptive statistics for the outcome variables. On average, children under five years old in Ghana have a height-for-age z-score around -1, with no significant difference between insured and non-insured individuals. Seventy percent of insured children do not have anemia. This is significantly lower for non-insured children by 10 percentage points.

Table 1: Descriptive statistics - Health outcomes

\begin{tabular}{lccc|ccc|cl}
\hline & \multicolumn{3}{c|}{ Insured } & \multicolumn{3}{c|}{ Not insured } & \multicolumn{3}{c}{ Difference } \\
\cline { 2 - 9 } & $\mathbf{N}$ & Mean & s.d. & N & Mean & s.d. & Diff & (t-stat) \\
\hline Height-for-age z-score & 3752 & -1.08 & 1.30 & 3200 & -1.07 & 1.44 & -0.008 & $(-0.15)$ \\
Not anemic & 2416 & 0.727 & 0.45 & 1807 & 0.607 & 0.49 & $0.119 * * *$ & $(5.82)$ \\
\hline
\end{tabular}

$* \mathrm{p}<0.1, * * \mathrm{p}<0.05, * * * \mathrm{p}<0.01$; Sampling weights have been used in computing the averages; Not anemic: hemoglobin $\geq 100 \mathrm{~g} / \mathrm{l} ; \mathrm{N}$ : number of observations; s.d.: standard deviations. 
Table 2: Descriptive statistics - Covariates

\begin{tabular}{|c|c|c|c|c|c|c|}
\hline & \multicolumn{2}{|c|}{ Insured } & \multicolumn{2}{|c|}{ Not insured } & \multicolumn{2}{|c|}{ Difference } \\
\hline & Mean & s.d. & Mean & s.d. & Diff & (t-stat) \\
\hline Male & 0.500 & 0.504 & 0.503 & 0.495 & -0.003 & -0.17 \\
\hline Age in days & 1002 & 485 & 781 & 540 & $221 * * *$ & 12.6 \\
\hline \multicolumn{7}{|l|}{ Mother's characteristics } \\
\hline Education: None ${ }^{a}$ & 0.310 & 0.466 & 0.347 & 0.472 & $-0.037 *$ & -1.84 \\
\hline Education: Primary & 0.206 & 0.408 & 0.231 & 0.417 & -0.024 & -1.46 \\
\hline Education: Middle/JSS & 0.349 & 0.481 & 0.338 & 0.469 & 0.012 & 0.60 \\
\hline Education: Secondary + & 0.134 & 0.343 & 0.084 & 0.275 & $0.050 * * *$ & 3.79 \\
\hline \multicolumn{7}{|l|}{ Household head's characteristics } \\
\hline Male & 0.791 & 0.410 & 0.785 & 0.407 & 0.006 & 0.31 \\
\hline Education & & & & & & \\
\hline Education: None ${ }^{a}$ & 0.276 & 0.451 & 0.295 & 0.452 & -0.019 & -1.00 \\
\hline Education: Primary & 0.138 & 0.347 & 0.191 & 0.389 & $-0.053 * * *$ & -3.67 \\
\hline Education: Middle/JSS & 0.387 & 0.491 & 0.374 & 0.479 & 0.014 & 0.65 \\
\hline Education: Secondary + & 0.199 & 0.403 & 0.141 & 0.344 & $0.058 * * *$ & 3.97 \\
\hline Ethnicity: Akan & 0.415 & 0.497 & 0.412 & 0.488 & 0.003 & 0.12 \\
\hline Ethnicity: Ga/Dangme & 0.070 & 0.258 & 0.095 & 0.291 & $-0.025 *$ & -1.94 \\
\hline Ethnicity: Ewe & 0.115 & 0.322 & 0.145 & 0.349 & $-0.030 *$ & -1.91 \\
\hline Ethnicity: Mole Dagbani ${ }^{\text {a }}$ & 0.217 & 0.416 & 0.160 & 0.364 & $0.056 * * *$ & 3.92 \\
\hline Ethnicity: Other & 0.183 & 0.390 & 0.187 & 0.386 & -0.004 & -0.26 \\
\hline Religion: Christian & 0.653 & 0.480 & 0.641 & 0.475 & 0.012 & 0.61 \\
\hline Religion: Muslim & 0.210 & 0.411 & 0.178 & 0.379 & $0.032 *$ & 1.81 \\
\hline Religion: Other religion ${ }^{a}$ & 0.070 & 0.257 & 0.097 & 0.293 & $-0.027 * * *$ & -2.67 \\
\hline Religion: No religion & 0.067 & 0.253 & 0.085 & 0.276 & -0.017 & -1.60 \\
\hline \multicolumn{7}{|l|}{ Household's characteristics } \\
\hline Urban & 0.451 & 0.502 & 0.403 & 0.486 & $0.048^{*}$ & 1.83 \\
\hline Region: Western & 0.088 & 0.285 & 0.112 & 0.313 & $-0.025^{*}$ & -1.6 \\
\hline Region: Central & 0.069 & 0.256 & 0.135 & 0.339 & $-0.066 * * *$ & -5.62 \\
\hline Region: Greater Accra & 0.122 & 0.330 & 0.186 & 0.385 & $-0.064 * * *$ & -2.85 \\
\hline Region: Volta & 0.078 & 0.270 & 0.087 & 0.279 & -0.009 & -0.65 \\
\hline Region: Eastern & 0.111 & 0.317 & 0.107 & 0.306 & 0.004 & 0.25 \\
\hline Region: Ashanti & 0.208 & 0.409 & 0.143 & 0.347 & $0.065 * *$ & 2.40 \\
\hline Region: Brong Ahafo & 0.111 & 0.317 & 0.064 & 0.242 & $0.048 * * *$ & 3.57 \\
\hline Region: Northern & 0.117 & 0.324 & 0.120 & 0.322 & -0.003 & -0.28 \\
\hline Region: Upper East & 0.054 & 0.228 & 0.029 & 0.166 & $0.025 * * *$ & 5.12 \\
\hline Region: Upper West ${ }^{\text {a }}$ & 0.042 & 0.203 & 0.018 & 0.131 & $0.025^{* * *}$ & 7.55 \\
\hline Number of household members & 5.888 & 2.795 & 5.987 & 2.556 & -0.099 & -0.99 \\
\hline Number of household children $<5$ years & 1.589 & 0.762 & 1.729 & 0.782 & $-0.139 * * *$ & -4.62 \\
\hline Average num. of people sleeping per room & 3.527 & 1.484 & 3.781 & 1.532 & $-0.254 * * *$ & -3.99 \\
\hline Wealth quintile & 3.000 & 1.406 & 2.652 & 1.360 & $0.348 * * *$ & 5.26 \\
\hline Distance to closest health care facility $(\mathrm{km})$ & 2.562 & 3.375 & 3.199 & 3.663 & $-0.636 * * *$ & -3.78 \\
\hline Distance to closest district capital $(\mathrm{km})$ & 11.17 & 10.00 & 13.16 & 10.47 & $-1.993 * * *$ & -4.06 \\
\hline $\mathrm{N}$ & 3832 & & 3260 & & & \\
\hline
\end{tabular}




\subsubsection{Covariates}

Covariates include information on the child, the mother and the household's head as well as household characteristics. Table 2 presents the descriptive statistics of these variables. Neither the gender of the child nor that of the household's head varies significantly between children with and without health insurance. However, on average, insured children are older, with both the mother and the household's head having a higher education. They are more likely to live in urban districts, closer to both health care facilities and district capitals, in wealthier households, with fewer children under five years old and fewer persons sleeping per room. There are also several disparities across ethnicities, religions and regions.

\section{Methods}

Comparing insured children's health to that of the non-insured would not lead to an identification of the effect of insurance on health. Insurance status may indeed be correlated with determinants of health status that would lead to selection into the treatment. For that reason, this paper uses matching methods to find a control group with units that are similar to the treatment group in term of their observable pre-treatment characteristics (Dehejia \& Wahba, 2002). Here, it implies pairing insured and non-insured children who are comparable but have different insurance statuses. When the number of observable characteristics is high, matching becomes more complex. This motivated Rosenbaum and Rubin (1983) to suggest the use of propensity scores to reduce the problem to a single dimension. This allows estimating the average treatment effect on the treated (ATT): the difference in health outcomes between insured and non-insured children who had the same probability of being insured.

Two assumptions are required in this setting. First, individuals with the same vector of covariates should have a positive probability of being either in the treatment or control group. This implies that a match can be found for each treated individual. In practice, the common support condition restricts the analysis to the observations that satisfy this condition. Second, potential outcomes should be independent of assignment into the treatment, given the propensity score (Smith \& Todd, 2005; Caliendo \& Kopeinig, 2008). The identifying assumption in this setting is therefore that selection into health insurance is exclusively based on observable characteristics. For this reason, I include a rich set of variables into the construction of the propensity score. Moreover, all information 
on insured and non-insured children comes from the same data source and is drawn from the same population. Heckman, Ichimura, and Todd (1997) and Heckman, Ichimura, Smith, and Todd (1998) show that matching estimators perform well in replicating the results of experimental estimators only when they are applied to data satisfying the previous criteria.

In practice, the propensity score, i.e. the probability of having insurance, is first estimated given a set of covariates. The propensity score has to satisfy the balancing property: observations with the same propensity score must have the same distribution of observable characteristics, irrespective of treatment status (Becker \& Ichino, 2002). Second, treated and control individuals are ranked with respect to their estimated propensity score. The analysis excludes treated individuals whose propensity score is outside the range of the control group's propensity scores (i.e., who are not in the common support area). This is the common support condition. Third, since this score is a continuous variable, several matching algorithms exist and differ in terms of the number, the weight and the selection of observations used to construct the counterfactual (Caliendo \& Kopeinig, 2008). Balancing tests can be used after matching to compare the obtained samples and determine which algorithm is the most effective in reducing the overall bias (Austin, 2009). The next section ensures that these requirements are met and discusses the common support area. Finally, once the after-matching control group is constructed, the ATT is estimated by comparing the mean of the outcome variable between the treatment and control groups.

\section{Results}

\subsection{Determinants of insurance membership}

Previous research has pointed towards several factors affecting the uptake of health insurance in Ghana. Education and gender are primary determinants of enrollment. Additional factors such as wealth, number of children, household structure, area of residence, religion and ethnicity also affect the uptake of health insurance (Amo, 2014; Amu \& Dickson, 2016; Dixon, Luginaah, \& Mkandawire, 2014; Owusu-Sekyere \& Chiaraah, 2014). Moreover, Buor (2003) shows that distance to a health care facility is the main cause of utilization of health services. 
Therefore, to later match individuals upon this score, I first estimate the probability of having health insurance with the following logit regression: ${ }^{9}$

$$
H I_{i}=\beta_{0}+\beta_{1} X_{C i}+\beta_{2} X_{M i}+\beta_{3} X_{H H i}+\beta_{4} X_{H i}+u_{i}
$$

$H I_{i}$ is an indicator of whether the child $i$ has health insurance, $X_{C i}, X_{M i}, X_{H H i}$ and $X_{H i}$ are vectors of, respectively, the child's, the mother's, the household head's and the household's characteristics. Child characteristics include gender and age. Mother characteristics consist of her level of education while the household head's characteristics comprise gender, the level of education, religion and ethnicity. Additionally, variables at the household level include the region and area (urban or rural) of residence, the distances both to the closest district capital (in which there is the district office of the NHIS) and to the closest health care facility, the number of household members, the average number of people sleeping per room, the number of children under five in the household, and the household wealth quintile. ${ }^{10}$

The same factors may also influence health outcomes. For example, wealth might affect both health and the decision to insure. Caregivers' education might also impact both the decision to get insurance and the health outcomes, as information on health, basic needs and care might be influenced by education. Other channels of possible selection, such as gender or age bias are included. Region, religion and ethnicity account for a lot of unobserved common beliefs and behaviors. Therefore, including these variables allows for the control of several channels of selection into health insurance, in order to ensure a robust matching.

Table 3 reports the results of this logit model. The estimation is of intrinsic interest as it highlights the determinants of enrollment into the NHIS for children. Previous research mainly focused on the determinants of adult enrollment. Older children, from a wealthier background, with a highly educated mother, with more household members and fewer siblings under five years old have a higher probability of having health insurance. The further the household is from the district capital, the lower the probability of insurance. Ethnicity and religion also have significant impacts on the probability of insurance. The probability of enrollment is significantly lower for each region compared to the Upper West region, except for the Upper East region. ${ }^{11}$ On the other hand, the child's and the household

\footnotetext{
${ }^{9}$ Results are similar if a probit regression is used instead.

${ }^{10}$ Results are similar if the wealth index is used instead of quintiles.

${ }^{11}$ The Upper West region is the region with the highest enrollment rates among children.
} 
head's gender do not significantly affect insurance status, nor does the distance to the closest health care facility.

\subsection{Propensity score and matching algorithm}

The propensity score estimated in the previous section satisfies the balancing property. In other words, children with the same probability of insurance have the same distribution of observable characteristics, regardless of their insurance status. I conduct balancing tests to select the algorithm that reduces the overall bias the most (see Appendix A). They indicate that radius matching leads to the most balanced sample, reducing the overall bias by $76 \%$. This leads to samples sufficiently balanced according to Rubin (2001). Radius matching implies matching each treated individual with all individuals in the control group who have a propensity score within a certain distance (called caliper). In the analysis the caliper is set at 0.01 , and robustness tests will ensure that the results are robust to the choice of the caliper. This technique allows reducing the variance of the estimator compared to nearest neighbor matching - since each individual has several matched control observations - while avoiding bad matches - since a tolerance level is imposed on the caliper (Caliendo $\&$ Kopeinig, 2008). Finally, the distribution of the propensity scores leads to a large common support area and therefore allows to find suitable matches. Treated individuals have an estimated propensity score in the interval $[0.032 ; 0.977]$ while control individuals have an estimated propensity score in the interval [0.023; 0.962]. For each estimation, the common support condition restricts the analysis to treated individuals that have a propensity score included in the support interval of control individuals, and for which matches exist within the caliper. This results in 6,926 observations in the analysis of HAZ and 4,206 for that of anemia; which corresponds to over $99.5 \%$ of the total sample. Appendix B graphically represents the distribution of the propensity scores.

\subsection{The impact of health insurance on health outcomes}

Table 4 presents the impact of health insurance on health outcomes among children under five years old. Having health insurance has a significant positive impact on both health indicators. Being insured brings the average height-for-age from 1.43 to 1.26 standard deviations below the median of the reference population and reduces the probability of having anemia by $20 \%$. 
Table 3: Probability of having health insurance

\begin{tabular}{|c|c|c|}
\hline Variables & Coef. & (s.e.) \\
\hline \multicolumn{3}{|l|}{ Child's characteristics } \\
\hline Male & 0.005 & $(0.082)$ \\
\hline Age in days & $0.006^{* * *}$ & $(0.001)$ \\
\hline Age in days ${ }^{2}$ & $-4.74 \mathrm{e}-06 * * *$ & $(9.95 e-07)$ \\
\hline Age in days ${ }^{3}$ & $1.23 \mathrm{e}-09 * * *$ & $(3.51 \mathrm{e}-10)$ \\
\hline \multicolumn{3}{|l|}{ Mother's characteristics: Education } \\
\hline Primary & 0.250 & $(0.154)$ \\
\hline Middle/JSS & 0.189 & $(0.140)$ \\
\hline Secondary + & $0.516^{* * *}$ & $(0.219)$ \\
\hline \multicolumn{3}{|l|}{ Household head's characteristics } \\
\hline Male & 0.008 & $(0.138)$ \\
\hline \multicolumn{3}{|l|}{ Education } \\
\hline Primary & -0.157 & $(0.150)$ \\
\hline Middle/JSS & 0.125 & $(0.162)$ \\
\hline Secondary + & 0.179 & $(0.195)$ \\
\hline \multicolumn{3}{|l|}{ Ethnicity } \\
\hline Akan & $-0.307 *$ & $(0.185)$ \\
\hline $\mathrm{Ga} /$ Dangme & -0.371 & $(0.237)$ \\
\hline Ewe & $-0.388^{*}$ & $(0.226)$ \\
\hline Other & -0.016 & $(0.131)$ \\
\hline \multicolumn{3}{|l|}{ Religion } \\
\hline Muslim & 0.214 & $(0.173)$ \\
\hline Christian & $0.292 *$ & $(0.162)$ \\
\hline No religion & 0.054 & $(0.213)$ \\
\hline \multicolumn{3}{|l|}{ Household's characteristics } \\
\hline Urban & $-0.302 *$ & $(0.157)$ \\
\hline \multicolumn{3}{|l|}{ Region } \\
\hline Western & $-1.657 * * *$ & $(0.241)$ \\
\hline Central & $-2.258 * * *$ & $(0.242)$ \\
\hline Greater Accra & $-2.494 * * *$ & $(0.300)$ \\
\hline Volta & $-1.293 * * *$ & $(0.291)$ \\
\hline Eastern & $-1.537 * * *$ & $(0.260)$ \\
\hline Ashanti & $-1.112 * * *$ & $(0.259)$ \\
\hline Brong Ahafo & $-0.524 * *$ & $(0.221)$ \\
\hline Northern & $-0.888 * * *$ & $(0.162)$ \\
\hline Upper East & -0.175 & $(0.179)$ \\
\hline Number of household members & $0.035^{*}$ & $(0.020)$ \\
\hline Number of household children $<5$ years & $-0.178 * *$ & $(0.069)$ \\
\hline Average number of people sleeping per room & $-0.063^{*}$ & $(0.037)$ \\
\hline Wealth quintile & $0.745^{* * *}$ & $(0.228)$ \\
\hline Wealth quintile ${ }^{2}$ & -0.055 & $(0.038)$ \\
\hline Distance to the closest health care facility & -0.012 & $(0.018)$ \\
\hline Distance to the closest district capital & $-0.011 * *$ & $(0.006)$ \\
\hline Constant & $-1.681 * * *$ & $(0.439)$ \\
\hline $\mathrm{N}$ & 7092 & \\
\hline
\end{tabular}


Table 4: Impact of health insurance on health outcomes

\begin{tabular}{lccccc}
\hline & N & Mean Control & ATT & \% effect & \multicolumn{1}{c}{$\boldsymbol{\Gamma}$} \\
\hline Height-for-age z-score & 6926 & -1.433 & $\begin{array}{l}0.172 * * * \\
(0.042)\end{array}$ & 12.0 & 1.25 \\
Not anemic & \multirow{2}{*}{4206} & 0.506 & $\begin{array}{l}0.103 * * * \\
(0.019)\end{array}$ & 20.4 & 1.4 \\
& & & & \\
\hline
\end{tabular}

$* \mathrm{p}<0.1, * * \mathrm{p}<0.05, * * * \mathrm{p}<0.01$; Propensity score (PS) matching with the radius algorithm (caliper: 0.01 ). Values in parentheses are standard errors bootstrapped with 500 replications. N: number of observations in the common support area; Mean Control: after matching mean of control group; ATT: mean of the treatment group (with NHIS) - mean of the control group, given the PS; $\Gamma$ : critical level of hidden bias from Rosenbaum bounds sensitivity analysis ( $10 \%$ level); Not anemic: hemoglobin $\geq 100 \mathrm{~g} / \mathrm{l}$.

The variance of the estimated treatment effect needs to consider the variance caused by the estimation of the propensity score and the matching procedure. I therefore bootstrap the standard errors of the estimated treatment effects to account for these additional sources of variability (see for example: Heckman et al., 1997; Dehejia \& Wahba, 2002; Black \& Smith, 2004; Sianesi, 2004).

The results rely on the assumption that the selection into treatment only depends on the observable characteristics used for matching. If there exist unobservable variables that affect insurance membership and health outcomes simultaneously, the propensity score matching estimators would not be consistent (Rosenbaum, 2002; DiPrete \& Gangl, 2004; Becker \& Caliendo, 2007). I check the incidence of this hidden bias using the Rosenbaum bounds sensitivity analysis. The last column of Table 4 presents the threshold level of hidden bias $(\Gamma)$ for which the significance of the results becomes questionable. For example, the value of 1.4 for anemia means that if children with the same vector of covariates differ in their odds of insurance by a factor of $40 \%$, the significance of the impact of the NHIS on anemia may be questionable. In other words, the magnitude of the hidden bias needs to be higher than 1.4 for the effect of health insurance to become spurious. ${ }^{12}$ Overall, the sensitivity analysis suggests that the estimates are quite robust to the potential endogeneity issue. To ensure that these results are not sensitive to the choice of the matching algorithm, Panel A of the table in Appendix C

12 This represents the worst-case scenario: the confidence interval of the estimate would include zero if the odds ratio of insurance membership differed by 1.4 because of an unobservable variable that was so strong as to nearly perfectly determine whether an insured child has a lower anemia than a noninsured child in each matched pair in the data (DiPrete \& Gangl, 2004). 
presents the results for other algorithms and other calipers for the radius matching. The results confirm that the estimates are robust to the choice of the algorithm.

\subsection{Heterogeneous impacts: Who benefits from health insurance?}

Even though the NHIS has a positive impact on health outcomes at the national level, the gains are not shared equally across regions. Four out of the ten regions do not present any significant improvement due to the NHIS in either of the two health measures. Those regions are the Greater Accra, the Ashanti, the Eastern and the Brong Ahafo regions. The point estimates in these regions are also smaller compared to the others. Appendix D presents the results of the analysis at the regional level. The aim of this section is to investigate whether the characteristics of the beneficiaries and the local conditions of the implementation of the NHIS might have led to this heterogeneous impact of the insurance scheme. In particular, as the NHIS aims at providing access to quality health care to all Ghanaians, I focus on the wealth of the beneficiaries and on the quality of the health care provision.

Conceptually, health insurance is expected to affect the relationship between wealth and access to health care. Indeed, health insurance is not only beneficial because it decreases the financial risk of medical expenditures, it can also provide access to care that would otherwise be unaffordable. This is known as the access value of health insurance (Nyman, 1999). In other words, it may remove a binding constraint and allow access to care for individuals who would otherwise forego or delay health care. This mechanism particularly applies to the lower-income households, who could therefore benefit more from health insurance than wealthier households, who may have access to alternative sources of treatment. This has been shown in other contexts (e.g. Xu et al., 2006; Hangoma, Robberstad, \& Aakvik, 2018).

In addition, the impact of removing user fees on health care crucially depends on the conditions of implementation (Ridde \& Morestin, 2011). In particular, the quality of health care provision should be at the center of health care policies (Rowe, de Savigny, Lanata, \& Victora, 2005; Cherlin et al., 2011). Mate et al. (2013) further point out that universal coverage schemes that only focus on expanding access to health care without addressing its quality may not improve the population's health. In Ghana specifically, one of the early lessons to be drawn from the impact of the NHIS on maternal health is that improving the quality of care is a necessary condition for improving health (Witter, Adjei, Armar-Klemesu, \& Graham, 2009). 
The analysis of the impact of the NHIS at the regional level suggests that the regions where the NHIS significantly affects children's health are indeed mainly those with a lower average wealth and a higher quality of public health care (see Appendix D). This is particularly true when one considers only the anemia outcome. The rest of the section is devoted to provide evidence on the heterogeneous impact of health insurance according to household wealth and public health care quality.

\subsubsection{The impact of health insurance on children's health according to household wealth}

To investigate whether household wealth affects the effectiveness of the NHIS, the sample is divided between children in households below and above the national median wealth. Figure 2 represents the impact of the NHIS on health outcomes for children in these two income groups. The average treatment effect of NHIS on height-for-age z-score is represented by a square marker and a dashed $95 \%$ confidence interval, while a round marker and a solid line represent the average treatment effect and the confidence interval for anemia. Only children in the lower part of the income distribution have a significant positive impact of the NHIS. Table 12 in Appendix E presents the complete results. Health insurance increases the HAZ by 0.19 standard deviations and the probability of not being anemic by 11.5 percentage points among children in the lower income. The impact of health insurance is statistically different between the lower-income group and the higher-income group. Table 13 in Appendix E presents some robustness checks and confirms that the results are robust to the choice of the income cutoff.

\subsubsection{The impact of health insurance on children's health according to health care quality}

Beyond beneficiaries' characteristics, local conditions of implementation are also expected to mitigate the impact of health insurance. Quality of care is one of them. The percentage of people within an administrative region who said that the government is doing very badly in handling improving basic health services is a proxy for the quality of care (Afrobarometer, 2012). ${ }^{13}$ Both the use of health care

${ }^{13}$ If one considers both very badly and fairly badly the results are weaker but point toward the same direction. 


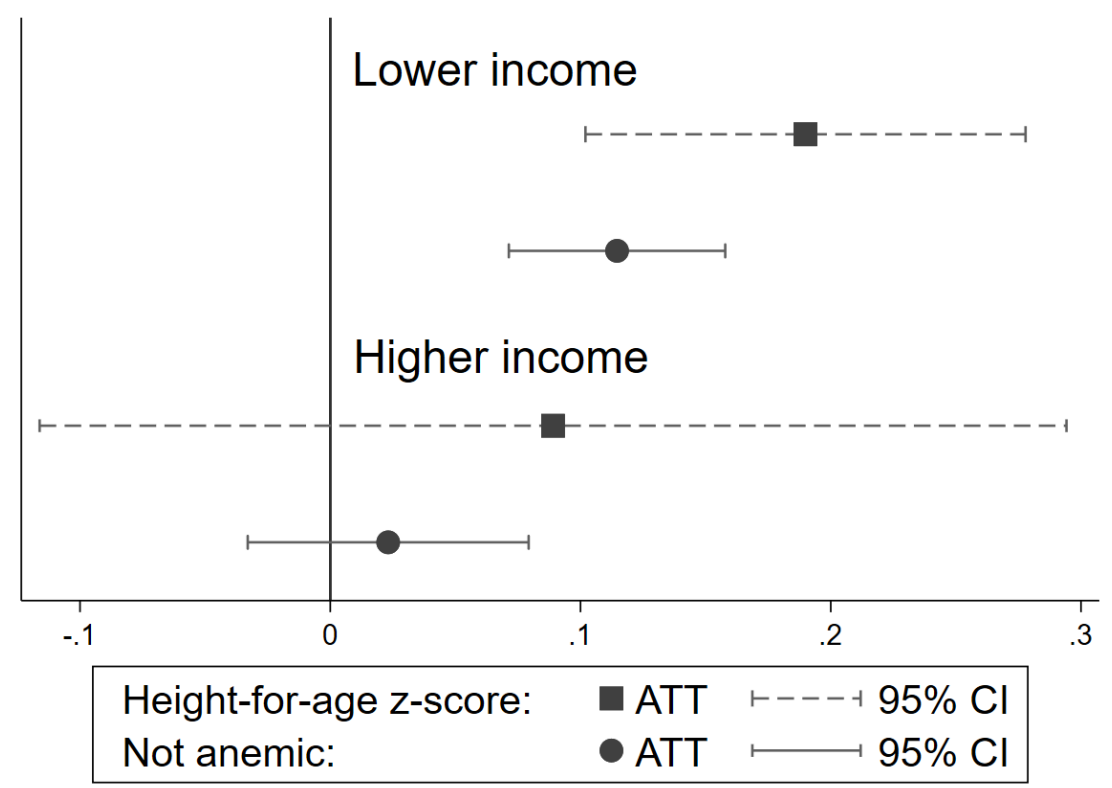

This figure represents the average treatment effect on the treated (ATT) of the NHIS on health outcomes and the 95\% confidence interval of these estimates (CI). The upper part of the graph represents the ATTs among children in the lower-income group (i.e. children whose household wealth index is lower than the national median) while the lower part of the graph represents the ATTs for children in the higher-income group. Not anemic: hemoglobin $\geq 100 \mathrm{~g} / \mathrm{l}$. In parentheses for each estimation: the number of observations in the common support area (N) and only if the estimate is significant at the $10 \%$ level, the critical level of hidden bias from Rosenbaum sensitivity analysis at the $10 \%$ level $(\Gamma)$ : Lower income, $\mathrm{HAZ}(\mathrm{N}=4,694 ; \Gamma=1.3)$, Lower income, not anemic $(\mathrm{N}=2,646 ; \Gamma=1.3)$, Higher income, $\operatorname{HAZ}(\mathrm{N}=2,223)$, Higher income, not anemic $(\mathrm{N}=1,542)$.

Figure 2: The impact of health insurance on health, by household wealth

and objective measures of quality of care influence health outcomes and are expected to correlate with this measure of perceived quality.

To assess the heterogeneity between quality levels, the total sample is divided according to perceived quality into two samples of five regions each. The five regions with a low perceived quality of public health care are the Ashanti, Brong Ahafo, Western, Eastern and Greater Accra regions. Figure 3 presents the results. The NHIS significantly improves health outcomes at the $5 \%$ level only for children living in high-quality regions. The complete table can be found in Appendix F. Even though for both health outcomes the impact of health insurance on health is larger among high-quality regions, the difference between quality groups is only significant for anemia results, at the $1 \%$ level. ${ }^{14}$ Caution

${ }^{14}$ Given that the perceptions of quality may vary between members and non-members of the NHIS (Duku et al., 2018), I conduct a robustness check to ensure that this result is not driven by the 
should be exercised in interpreting these results. I do not claim to identify the causal impact of quality on the NHIS effectiveness, however, these tests provide evidence that the gains of the NHIS are concentrated in the group of regions with a high perceived quality of public care.

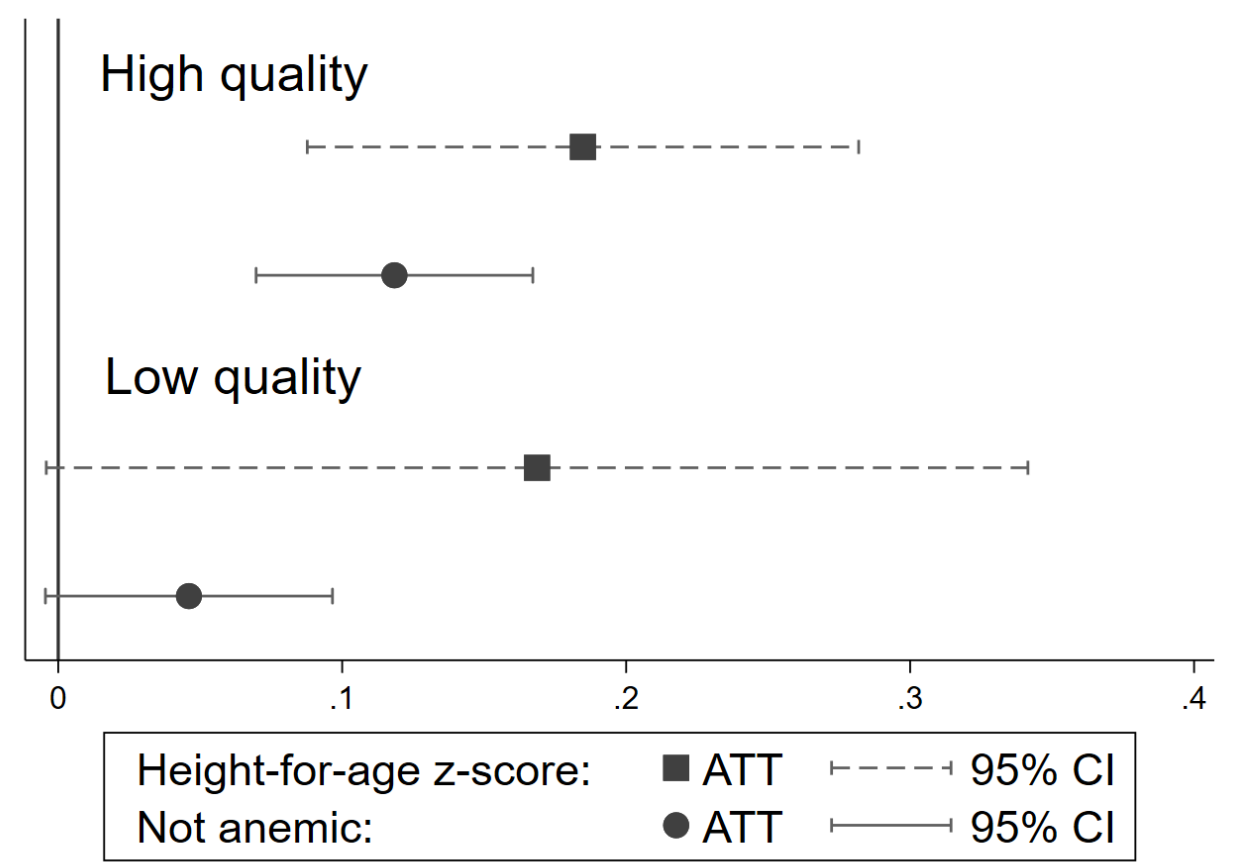

This figure represents the average treatment effect on the treated (ATT) of the NHIS on health outcomes and the 95\% confidence interval of these estimates (CI). The upper part of the graph represents the ATTs among children living in a region with a high quality of care (i.e. the five regions with the lower share of respondents who state that the government is doing very badly at improving basic health services, i.e. Northern, Upper East, Upper West, Volta and Central) while the lower part of the graph represents the ATTs for children in the low quality group. Not anemic: hemoglobin $\geq 100 \mathrm{~g} / \mathrm{l}$. In parentheses for each estimation: the number of observations in the common support area (N) and only if the estimate is significant at the $10 \%$ level, the critical level of hidden bias from Rosenbaum sensitivity analysis at the $10 \%$ level $(\Gamma)$ : High quality, $\mathrm{HAZ}(\mathrm{N}=5,150 ; \Gamma=1.3)$, High quality, not anemic $(\mathrm{N}=2,627$; $\Gamma=1.4)$, Low quality, $\operatorname{HAZ}(\mathrm{N}=1,752 ; \Gamma=1.2)$, Low quality, not anemic $(\mathrm{N}=1,553 ; \Gamma=1.35)$.

Figure 3: The impact of health insurance on health, by health care quality

insurance coverage within a region. There is no significant difference in the impact of NHIS across regions with a low or a high insurance coverage among children under five years old. The results are available in Appendix G. 


\subsubsection{The impact of health insurance on children's health according to household wealth and health care quality}

As mentioned in the previous section, the measure of quality is a perceived measure. This has advantages because it drives trust and health care utilization, but one could fear that it would be correlated with wealth. For example, this would happen if those with higher income were more likely to say that the quality of services is low.

Since the quality measure is averaged at the regional level but the wealth measure is available at the household level, one way to address this issue is to look at different income groups within each quality group. This removes part of the variance as it allows for the comparison of children from households with different wealth, within the regions of a given quality. Besides being more robust to endogeneity, this analysis looks at the heterogeneous impact of health insurance across both quality and income groups simultaneously.

Figure 4 represents the average treatment effect of the NHIS on the two health outcomes, across the four sub-groups: children in households with lower or higher income living in regions with a low or high quality of care. It indicates that the positive impact of the NHIS is concentrated among the lower-income households living in high-quality regions. In other words, it is the interaction between the quality of supply (quality of care) and the type of recipient (income) that matters to understand the heterogeneous impact of the NHIS in Ghana (see Appendix H for the complete table).

\subsection{Channel: health care utilization}

So far, I have looked at the direct impact of having health insurance on children's health outcomes. However, this impact likely operates through health care utilization. Further analysis looking at the impact of the NHIS on health care utilization allows to disentangle two possible causes driving the inefficiency of the NHIS on health outcomes. Either the NHIS has no impact on the use of care of its members - hence no health effect - or NHIS members increase their use of health care but this does not translate into a better health status (Levy \& Meltzer, 2001). This section investigates this question to better grasp the impact of the NHIS on health. 


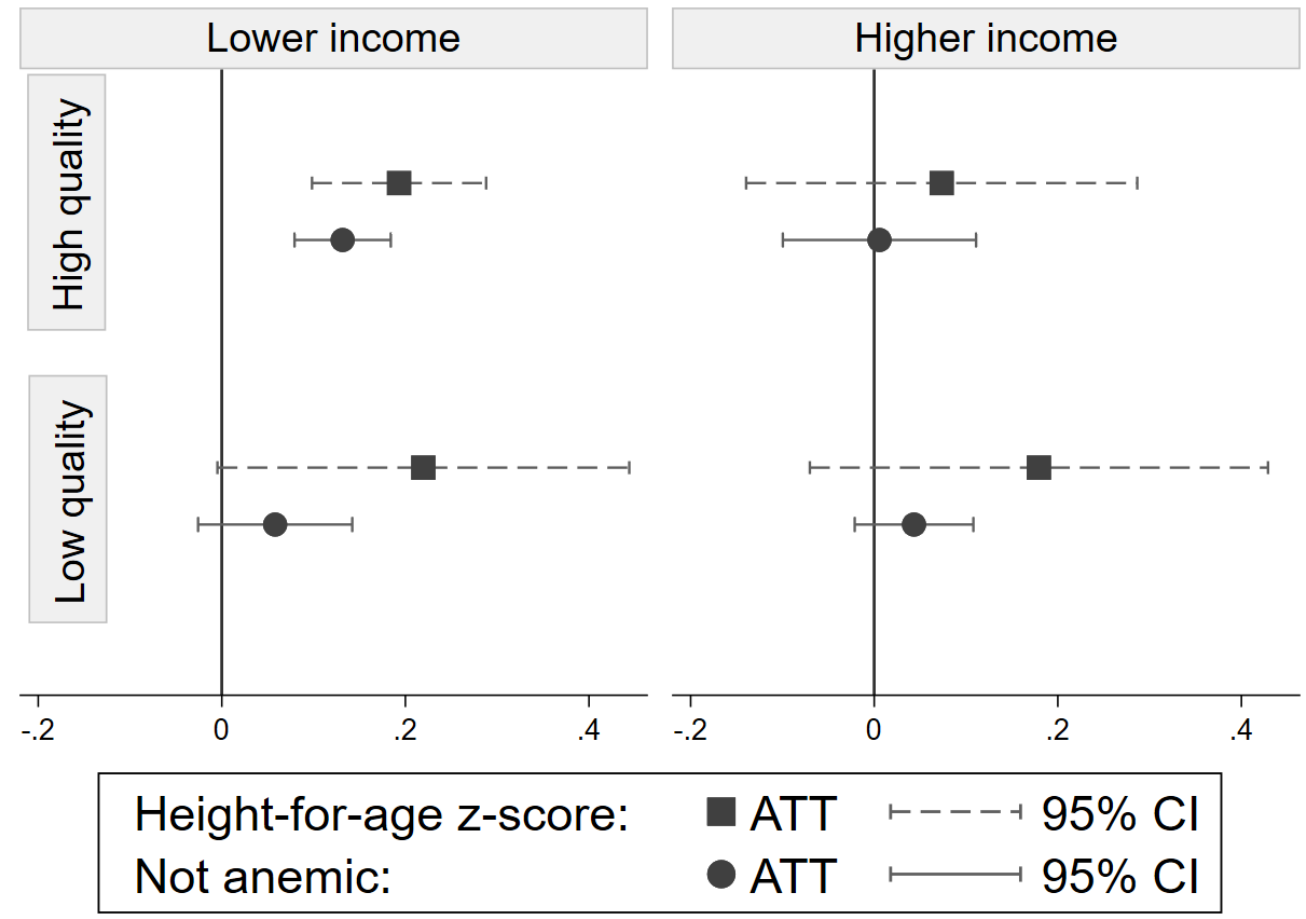

This figure represents the average treatment effect on the treated (ATT) of the NHIS on health outcomes and the 95\% confidence interval of these estimates (CI). The graph is divided into four quadrants. The two upper quadrants represent the ATTs among children living in a region with a high quality (HQ) of care (i.e. the five region with the lower share of respondents who state that the government is doing very badly at improving basic health services, i.e. Northern, Upper East, Upper West, Volta and Central). The two lower quadrants of the graph represents the ATTs for children in the low quality (LQ) group. The two quadrants situated in the left panel the graph represents the ATTs among children in the lower-income (LI) group (i.e. children whose household wealth index is lower than the national median) while the right panel of the graph represents the ATTs for children in the higher-income (HI) group. Not anemic: hemoglobin $\geq 100 \mathrm{~g} / \mathrm{l}$. In parentheses for each estimation: the number of observations in the common support area $(\mathrm{N})$ and only if the estimate is significant at the $10 \%$ level, the critical level of hidden bias from Rosenbaum sensitivity analysis at the $10 \%$ level $(\Gamma)$ : HQ and LI, HAZ (N=3,972; $\Gamma=1.3)$; HQ and LI, not anemic $(\mathrm{N}=2,005 ; \Gamma=1.4), \mathrm{HQ}$ and HI, HAZ $(\mathrm{N}=1,150)$, HQ and HI, not anemic $(\mathrm{N}=571)$, LQ and LI, HAZ (N=719; $\Gamma=1.2)$, LQ and LI, not anemic ( $\mathrm{N}=636)$, LQ and HI, HAZ ( $\mathrm{N}=1,024)$, LQ and HI, not anemic ( $\mathrm{N}=909)$.

Figure 4: The impact of health insurance on health, by wealth and health care quality

\subsubsection{Data}

To investigate the use of health care among children, in this section I restrict the analysis to children who had fever in the past two weeks. I use two different variables. The first one represents the use of health care facility (HCF). It is equal to one for children who went to a HCF during their previous illness (Use of $H C F$ ). To complement the analysis, I also look at the outcome of choosing to go to a HCF instead of other kind of treatments. This analysis restricts the sample to children who did seek for treatment or advice during this illness and the variable is equal to one for children who went to a HCF 
during their previous illness (Chose HCF for treatment). This second variable examines the choice of using HCF over other kind of treatment and potentially eliminates the least severe illnesses from the analysis.

Table 5 presents the descriptive statistics of these two variables. ${ }^{15}$ About $61 \%$ of insured children went to a HCF during their illness while this amounts to $33 \%$ among non-insured children. Conditional on seeking for some kind of treatment or advice, $85 \%$ of insured children and $67 \%$ of non-insured children went to a HCF. Both differences are significant at the $1 \%$ level. The positive difference in Chose HCF for treatment can be interpreted as a shift toward the use of HCF compared to other kind of treatment among insured children compared to the non-insured.

Table 5: Descriptive statistics - Health care utilization

\begin{tabular}{lccc|ccc|cc}
\hline & \multicolumn{3}{c|}{ Insured } & \multicolumn{3}{c|}{ Not insured } & \multicolumn{2}{c}{ Difference } \\
\cline { 2 - 9 } & $\mathbf{N}$ & Mean & s.d. & N & Mean & s.d. & Diff & (t-stat) \\
\hline $\begin{array}{l}\text { Use of HCF } \\
\begin{array}{l}\text { Chose HCF for } \\
\text { treatment }\end{array}\end{array}$ & 1028 & 0.612 & 0.494 & 691 & 0.326 & 0.460 & $0.286^{* * *}$ & $(7.20)$ \\
& 773 & 0.851 & 0.368 & 306 & 0.667 & 0.438 & $0.185^{* * *}$ & $(4.18)$ \\
\hline
\end{tabular}

$* \mathrm{p}<0.1, * * \mathrm{p}<0.05$, *** $\mathrm{p}<0.01$; Sampling weights have been used in computing the averages. HCF: Health care facility; Use of $\mathrm{HCF}=1$ if the child who had fever in the past two weeks went to a HCF; Chose HCF for treatment = 1 if the child who had fever in the past two weeks and who sought for treatment or advice, went to a HCF. N: number of observations; s.d.: standard deviations.

\subsubsection{The impact of health insurance on health care utilization}

Table 6 presents the impact of the NHIS on health care utilization. Children have two times more chances to go to a health care facility if they are insured. Also only among children seeking for treatment or advice, children have a $40 \%$ higher probability to go to a health care facility if insured. This suggests that the NHIS increases the use of health care and implies a shift toward the use of health care facilities away from other kind of treatment. This is in line with the hypothesis that the increase in health care utilization is a channel for improved health outcomes, since at the national level the NHIS has a positive impact on health outcomes.

${ }^{15}$ Nearly one in five children had fever in the past two weeks, which leads the sample size to 1,719 children. This proportion is high but it should be noted that the survey was conducted in the late rainy season when childhood febrile illnesses are most common (Ghana Statistical Office, 2011). 
Table 6: Impact of health insurance on health care utilization

\begin{tabular}{|c|c|c|c|c|c|}
\hline & $\mathbf{N}$ & Mean Control & ATT & $\%$ effect & $\Gamma$ \\
\hline$\overline{\text { Use of HCF }}$ & 1673 & 0.292 & $\begin{array}{c}0.338 * * * \\
(0.031)\end{array}$ & 115.8 & 3.75 \\
\hline Chose HCF for treatment & 1038 & 0.611 & $\begin{array}{c}0.228 * * * \\
(0.041)\end{array}$ & 37.3 & 2.4 \\
\hline
\end{tabular}

$* \mathrm{p}<0.1, * * \mathrm{p}<0.05, * * * \mathrm{p}<0.01$; Propensity score (PS) matching with the radius algorithm (caliper: 0.01 ). Values in parentheses are standard errors bootstrapped with 500 replications. N: number of observations in the common support area; Mean Control: after matching mean of control group; ATT: mean of the treatment group (with NHIS) - mean of the control group, given the PS; $\Gamma$ : critical level of hidden bias from Rosenbaum bounds sensitivity analysis (10\% level). HCF: Health care facility; Use of HCF $=1$ if the child who had fever in the past two weeks went to a HCF; Chose HCF for treatment $=1$ if the child who had fever in the past two weeks and who sought for treatment or advice, went to a HCF.

The Rosenbaum bounds sensitivity analysis suggests that the results are quite robust to the endogeneity issue. Indeed, as long as the hidden bias affecting the odds of being insured is not higher than $375 \%$ and $240 \%$, the significance of the result is robust to the endogeneity of unobserved variables. Additionally, panel B of the table in Appendix C confirms that this result is robust to other matching algorithms.

\subsubsection{Heterogeneous impact: The impact of insurance membership on children's health care utilization according to household wealth and health care quality}

The analysis of the impact of the NHIS on health outcomes revealed important heterogeneities across both income and quality groups. This section is devoted to analyzing the impact of the NHIS on health care utilization according to these two dimensions in order to better grasp the heterogeneous effect of the NHIS on health. ${ }^{16}$

Table 7 presents the results of the heterogeneous impact of the NHIS on health care utilization. The NHIS has a positive impact on the likelihood of visiting a health care facility for all children. Regarding the differentiated impact according to health care quality, the NHIS affects the choice of going to a HCF conditional on having sought for some treatment only in regions with a high quality of care. This suggests that in regions with a higher quality of the care, health insurance increases the

${ }^{16}$ The analysis cannot be conducted at the regional level because of the sample size of children ill with fever in the past two weeks. 
overall utilization of health care and induces a shift toward the use of health care facilities as a source of treatment. While in regions with a lower quality of care, health insurance increases the overall utilization of health care facilities but does not significantly induce a change in the sources of treatment. ${ }^{17}$ Combined with the direct effect of quality of care on health, this result is likely to explain why children living in regions with a higher quality of care have better health outcomes.

Besides the effect of quality, the NHIS has also differentiated impact on children according to wealth. Children in the lower-income group gain more from the NHIS. The conceptual rationale for this effect is that health insurance removes binding financial constraints for the poorest households. To test this hypothesis, I consider a more costly procedure than visiting a health facility: having blood testing during the last illness. Table 8 presents the effect of the NHIS on this variable, according to the different income groups. This confirms that health insurance has a significant and positive effect on the probability of having a blood test for children in the lower income group (increase by 200\%) while it has no significant effect for the children in the higher income group. This difference across the two income groups is significant at the $5 \%$ level.

In conclusion, the NHIS increases the probability of visits to health care facilities in regions with low quality of care, but this does not translate into health gains. In contrast, regions where the quality of care is high present an increase in the use of health care facilities and a switch toward the use of health care facilities with respect to other sources of treatment or medical advice. This translates into health gains for insured children. With respect to wealth, the NHIS increases the probability of having higher-level procedures only among children in the lower-income group. This is suggestive that the NHIS removes barriers to access to higher-level procedure and therefore implies health benefits only among children in the low-income segment.

17 The average treatment effect of health insurance on Choose HCF for treatment is significantly different at the $1 \%$ level between regions of high and low quality. 
Table 7: Impact of health insurance on health care utilization - By wealth and health care quality

\begin{tabular}{|c|c|c|c|c|c|c|c|c|c|c|c|c|c|c|c|c|}
\hline \multirow{3}{*}{$\begin{array}{l}\text { Region } \\
\text { Household }\end{array}$} & \multicolumn{8}{|c|}{ High quality } & \multicolumn{8}{|c|}{ Low quality } \\
\hline & \multicolumn{3}{|c|}{ Lower income } & & \multicolumn{4}{|c|}{ Higher income } & \multicolumn{3}{|c|}{ Lower income } & & \multicolumn{4}{|c|}{ Higher income } \\
\hline & Mean C & ATT & $\%$ & $\Gamma$ & Mean C & ATT & $\%$ & $\Gamma$ & Mean C & ATT & $\%$ & $\Gamma$ & Mean C & ATT & $\%$ & $\Gamma$ \\
\hline $\begin{array}{c}\text { Use of HCF } \\
{[\mathrm{N}]}\end{array}$ & 0.272 & $\begin{array}{c}0.371 * * * \\
(0.03) \\
{[1,120]}\end{array}$ & 136.4 & 4.35 & 0.281 & $\begin{array}{c}0.333 * * * \\
(0.09) \\
{[210]}\end{array}$ & 118.5 & 2.2 & 0.292 & $\begin{array}{c}0.240 * * \\
(0.10) \\
{[155]}\end{array}$ & 82.2 & 1.95 & 0.356 & $\begin{array}{c}0.284 * * \\
(0.12) \\
{[129]}\end{array}$ & 79.8 & 1.3 \\
\hline $\begin{array}{l}\text { Chose } \mathrm{HCF} \\
\text { for treatment } \\
\qquad[\mathrm{N}]\end{array}$ & 0.618 & $\begin{array}{c}0.205 * * * \\
(0.05) \\
{[689]}\end{array}$ & 33.2 & 2.05 & 0.456 & $\begin{array}{c}0.415 * * * \\
(0.12) \\
{[116]}\end{array}$ & 91.0 & 2.25 & 0.596 & $\begin{array}{c}0.246 \\
(0.17) \\
{[74]}\end{array}$ & 41.3 & & 0.824 & $\begin{array}{c}-0.019 \\
(0.13) \\
{[69]}\end{array}$ & -2.3 & \\
\hline
\end{tabular}

$* \mathrm{p}<0.1, * * \mathrm{p}<0.05, * * * \mathrm{p}<0.01$. Propensity score matching with radius of caliper 0.01 ; Values in parentheses are standard errors bootstrapped with 500 replications and values in brackets are the number of observations in the common support area $(\mathrm{N})$; Mean $\mathrm{C}$ : after matching mean of control group; ATT: mean of the treatment group (with NHIS) - mean of the control group, given the propensity score; $\Gamma$ : critical level of hidden bias from Rosenbaum bounds sensitivity analysis ( $10 \%$ level), reported only if $\mathrm{p}<0.1$; Quality: Data from the Afrobarometer: by region, share of respondents who answered very badly to the question "How does the government handles improving basic health services?" on a 4-item scale. High quality regions: five regions with lower share of respondents who said very badly, i.e. Northern, Upper East, Upper West, Volta and Central regions; Lower income: if household wealth index is lower than the national median; HCF: Health care facility; Use of HCF $=1$ if the child who had fever in the past two weeks went to a HCF; Chose HCF for treatment $=1$ if the child who had fever in the past two weeks and who sought for treatment or advice, went to a HCF. 
Table 8: Impact of health insurance on blood testing probability - By wealth

\begin{tabular}{|c|c|c|c|c|c|c|c|c|}
\hline \multirow[t]{2}{*}{ Household: } & \multicolumn{4}{|c|}{ Lower income } & \multicolumn{3}{|c|}{ Higher income } & \\
\hline & Mean C & ATT & $\%$ & $\Gamma$ & Mean C & ATT & $\%$ & Difference \\
\hline Blood testing & 0.079 & $\begin{array}{l}0.161 * * * \\
(0.02)\end{array}$ & 203.8 & 3.2 & 0.132 & $\begin{array}{l}0.078 \\
(0.05)\end{array}$ & 59.1 & $\begin{array}{l}0.083 * * \\
(0.03)\end{array}$ \\
\hline$[\mathrm{N}]$ & & {$[1,280]$} & & & & [361] & & \\
\hline
\end{tabular}

$* \mathrm{p}<0.1, * * \mathrm{p}<0.05, * * * \mathrm{p}<0.01$; Propensity score (PS) matching with the radius algorithm (caliper: 0.01 ). Values in parentheses are standard errors and values in brackets are the number of observations in the common support area $(\mathrm{N})$; Standard errors of the ATTs are bootstrapped with 500 replications; Mean C: after matching mean of control group; ATT: mean of the treatment group (with NHIS) - mean of the control group, given the PS; Lower income: if household wealth index is lower than the national median.

\section{Conclusion}

The impact of health insurance on health in developing countries has so far led to mixed results in the literature. Previous studies have either focused on the national averages of the impact of health insurance or looked at specific local settings. This paper contributes to this literature by reconciling some of the conflicting results and shedding new light on the conditions under which the national health insurance scheme in Ghana was successful in improving children's health.

Even though national averages suggest that the NHIS improves health outcomes for children, gains are not shared equally and several regions do not significantly benefit from the scheme. Investigating the origin of these regional disparities reveals that both the characteristics of the beneficiaries and the local conditions of implementation are relevant to the effectiveness of the scheme. Gains are indeed concentrated in lower-income households living in regions where the quality of public health care is high. Further evidence points to the importance of health care utilization to explain these results.

For those aiming at implementing a large-scale insurance scheme, three considerations should be remembered. First, the recipient's wealth is an important factor for the effectiveness of health insurance. Children in lower-income groups benefit more from insurance membership, by getting access to higher-level care that would otherwise be unaffordable. Therefore, a large-scale insurance program may have potential equity benefits. However, this positive outcome should not conceal the fact that wealth may still be a significant barrier to insurance take-up. Besides removing user fees, other policies might increase enrollment rates. Gaddah and Munro (2011) indeed show that there is a strong complementarity between subsidies and information for increasing the use of health services and 
improving health outcomes. Second, the quality of the health care services is not surprisingly a relevant factor in the effectiveness of health insurance. Clinical audits should be undertaken to understand where the challenges are most important and effective monitoring should be strengthened to guarantee improvements in quality. Third, these two considerations about wealth and quality cannot be disentangled. Reaching out to a large number of households in the lowest-income segment is insufficient if it is not coupled with an improvement in the quality of care.

As a conclusion, evaluations of large-scale policies should take local conditions into account. When diversity is significant, it seems important to assess the extent to which national averages are representative of regional realities. Both supply and demand are relevant to understand the effectiveness of such schemes, and further analysis could reveal the true beneficiaries of these policies. Finally, additional research should deepen the investigation of the causes of lack of impact of health insurance in some contexts in order to be able to design the most effective policies.

\section{References}

[dataset] Afrobarometer Data, Ghana, Round 5, 2012, available at http://www.afrobarometer.org.

Aggarwal, A. (2010). Impact evaluation of India's 'Yeshasvini' community-based health insurance programme. Health Economics, 19(S1), 5-35. https://doi.org/10.1002/hec.1605

Akin, J. S., Birdsall, N., \& de Ferranti, D. M. (1987). Financing health services in developing countries: an agenda for reform. Washington: World Bank Policy Study.

Alhassan, R. K., Nketiah-Amponsah, E., \& Arhinful, D. K. (2016). A Review of the National Health Insurance Scheme in Ghana: What are the Sustainability Threats and Prospects? PloS One, 11(11), e0165151. https://doi.org/10.1371/journal.pone.0165151

Amo, T. (2014). The National Health Insurance Scheme (NHIS) in the Dormaa Municipality, Ghana: Why Some Residents Remain Uninsured? Global Journal of Health Science, 6(3), 82. https://doi.org/10.5539/gjhs.v6n3p82

Amu, H., \& Dickson, K. S. (2016). Health insurance subscription among women in reproductive age in Ghana: do socio-demographics matter? Health Economics Review, 6(1), 24. https://doi.org/10.1186/s13561-016-0102-x

Andoh-Adjei, F. X., Nsiah-Boateng, E., Asante, F. A., Spaan, E., \& van der Velden, K. (2018). Perception of quality health care delivery under capitation payment: a cross-sectional survey of health 
insurance subscribers and providers in Ghana. BMC Family Practice, 19(1), 37. https://doi.org/10.1186/s12875-018-0727-4

Ansah, E. K., Narh-Bana, S., Asiamah, S., Dzordzordzi, V., Biantey, K., Dickson, K., ... \& Whitty, C. J. (2009). Effect of removing direct payment for health care on utilisation and health outcomes in Ghanaian children: a randomised controlled trial. PLoS Medicine, 6(1), e1000007. https://doi.org/10.1371/journal.pmed.1000007

Aryeetey, G. C., Westeneng, J., Spaan, E., Jehu-Appiah, C., Agyepong, I. A., \& Baltussen, R. (2016). Can health insurance protect against out-of-pocket and catastrophic expenditures and also support poverty reduction? Evidence from Ghana's National Health Insurance Scheme. International Journal for Equity in Health, 15(1), 116. https://doi.org/10.1186/s12939-016-0401-1

Asuming, P. O. (2013). Getting the poor to enroll in health insurance, and its effects on their health: Evidence from a field experiment in Ghana. Mimeo.

Austin, P. C. (2009). Balance diagnostics for comparing the distribution of baseline covariates between treatment groups in propensity-score matched samples. Statistics in Medicine, 28(25), 30833107. https://doi.org/10.1002/sim.3697

Barros, R. (2008). Wealthier but not much healthier: effects of a health insurance program for the poor in Mexico. Stanford Institute for Economic Policy Research (SIEPR) Discussion Paper 09002 .

Becker, S. O., \& Caliendo, M. (2007). Sensitivity analysis for average treatment effects. The Stata Journal, 7(1), 71-83. https://doi.org/10.1177/1536867X0700700104

Becker, S. O., \& Ichino, A. (2002). Estimation of average treatment effects based on propensity scores. The Stata Journal, 2(4), 358-377. https://doi.org/10.1177/1536867X0200200403

Black, D. A., \& Smith, J. A. (2004). How robust is the evidence on the effects of college quality? Evidence from matching. Journal of Econometrics, 121(1-2), 99-124. https://doi.org/10.1016/j.jeconom.2003.10.006

Bosomprah, S., Ragno, P. L., Gros, C., \& Banskota, H. (2015). Health insurance and maternal, newborn services utilisation and under-five mortality. Archives of Public Health,73(1), 51. https://doi.org/10.1186/s13690-015-0101-0

Browne, J. L., Kayode, G. A., Arhinful, D., Fidder, S. A., Grobbee, D. E., \& KlipsteinGrobusch, K. (2016). Health insurance determines antenatal, delivery and postnatal care utilisation: evidence from the Ghana Demographic and Health Surveillance data. BMJ Open, 6(3), e008175. https://doi.org/10.1136/bmjopen-2015-008175 
Brugiavini, A., \& Pace, N. (2016). Extending health insurance in Ghana: effects of the National Health Insurance Scheme on maternity care.Health Economics Review, 6(1), 7. https://doi.org/10.1186/s13561-016-0083-9

Buor, D. (2003). Analysing the primacy of distance in the utilization of health services in the Ahafo-Ano South district, Ghana. The International Journal of Health Planning and Management, 18(4), 293-311. https://doi.org/10.1002/hpm.729

Caliendo, M., \& Kopeinig, S. (2008). Some practical guidance for the implementation of propensity score matching. Journal of Economic Surveys, 22(1), 31-72. https://doi.org/10.1111/j.14676419.2007.00527.x

Chen, Y., \& Jin, G. Z. (2012). Does health insurance coverage lead to better health and educational outcomes? Evidence from rural China. Journal of Health Economics, 31(1), 1-14. https://doi.org/10.1016/j.jhealeco.2011.11.001

Cherlin, E. J., Allam, A. A., Linnander, E. L., Wong, R., El-Toukhy, E., Sipsma, H., ... \& Bradley, E. H. (2011). Inputs to quality: supervision, management, and community involvement in health facilities in Egypt in 2004. BMC health services research,11(1), 282. https://doi.org/10.1186/1472-6963-11-282

Dehejia, R. H., \& Wahba, S. (2002). Propensity score-matching methods for nonexperimental causal studies. Review of Economics and Statistics, 84(1), 151-161. https://doi.org/10.1162/003465302317331982

DiPrete, T. A., \& Gangl, M. (2004). Assessing Bias in the Estimation of Causal Effects: Rosenbaum Bounds on Matching Estimators and Instrumental Variables Estimation with Imperfect Instruments. Sociological Methodology,34(1), 271-310. https://doi.org/10.1111/j.00811750.2004.00154.x

Dixon, J. (2011). Financing national health insurance in Ghana. Africa Portal: Backgrounder, 8.

Dixon, J., Luginaah, I., \& Mkandawire, P. (2014). The National Health Insurance Scheme in Ghana's Upper West region: A gendered perspective of insurance acquisition in a resource-poor setting. Social Science \& Medicine, 122, 103-112. https://doi.org/10.1016/j.socscimed.2014.10.028

Dixon, J., Tenkorang, E. Y., \& Luginaah, I. (2013). Ghana's National Health Insurance Scheme: a national level investigation of members' perceptions of service provision. $B M C$ International Health and Human Rights, 13(1), 35. https://doi.org/10.1186/1472-698X-13-35

Dixon, J., Tenkorang, E. Y., Luginaah, I. N., Kuuire, V. Z., \& Boateng, G. O. (2014). National health insurance scheme enrolment and antenatal care among women in Ghana: is there any 
relationship? Tropical Medicine \& International Health, 19(1), 98-106. https://doi.org/10.1111/tmi.12223

Dow, W. H., \& Schmeer, K. K. (2003). Health insurance and child mortality in Costa Rica. Social Science \& Medicine, 57(6), 975-986. https://doi.org/10.1016/S0277-9536(02)00464-1

Drislane, F. W., Akpalu, A., \& Wegdam, H. H. (2014). The medical system in Ghana. Yale Journal of Biology and Medicine, 87(3), 321-326.

Duku, S. K. O., Nketiah-Amponsah, E., Janssens, W., \& Pradhan, M. (2018). Perceptions of healthcare quality in Ghana: Does health insurance status matter? PloS One, 13(1), e0190911. https://doi.org/10.1371/journal.pone.0190911

Durairaj, V., D’Almeida, S., \& Kirigia, J. (2010). Obstacles in the process of establishing sustainable National Health Insurance Scheme: insights from Ghana. Technical Brief for PolicyMakers. Accra: World Health Organization.

Dwumoh, D., Essuman, E. E., \& Afagbedzi, S. K. (2014). Determinant of factors associated with child health outcomes and service utilization in Ghana: multiple indicator cluster survey conducted in 2011. Archives of Public Health, 72(1), 42. https://doi.org/10.1186/2049-3258-72-42

Dzakpasu, S., Soremekun, S., Manu, A., ten Asbroek, G., Tawiah, C., Hurt, L., ... \& Kirkwood, B. R. (2012). Impact of free delivery care on health facility delivery and insurance coverage in Ghana's Brong Ahafo Region. PloS One, 7(11), e49430. https://doi.org/10.1371/journal.pone.0049430

Ewusie, J. E., Ahiadeke, C., Beyene, J., \& Hamid, J. S. (2014). Prevalence of anemia among under-5 children in the Ghanaian population: estimates from the Ghana demographic and health survey. BMC public health, 14(1), 626. https://doi.org/10.1186/1471-2458-14-626

Fink, G., Robyn, P. J., Sié, A., \& Sauerborn, R. (2013). Does health insurance improve health? Evidence from a randomized community-based insurance rollout in rural Burkina Faso. Journal of Health Economics, 32(6), 1043-1056.

Gaddah, M., \& Munro, A. (2011). The progressivity of health care services in Ghana. National Graduate Institute for Policy Studies (GRIPS) Discussion Paper, 11-14.

Gajate-Garrido, G., \& Owusua, R. (2013). The national health insurance scheme in Ghana: Implementation challenges and proposed solutions. IFPRI Discussion Paper 01309.

Gertler, P., Locay, L., \& Sanderson, W. (1987). Are user fees regressive? The welfare implications of health care financing proposals in Peru. Journal of econometrics, 36(1-2), 67-88. https://doi.org/10.1016/0304-4076(87)90044-3 
Ghana Statistical Service (2011). "Ghana Multiple Indicator Cluster Survey with an enhanced malaria module and biomarker, 2011." Final Report. Accra, Ghana.

Giedion, U., \& Diaz, B. Y. (2010). A review of the evidence. In M.-L. Escobar, C. C. Griffin, \& P. R. Shaw (Eds.), The impact of health insurance in low and middle income countries (13-32). Washington, DC: Brookings Institution Press.

Gilson, L., \& McIntyre, D. (2005). Removing user fees for primary care in Africa: the need for careful action. BMJ, 331, 762-765. https://doi.org/10.1136/bmj.331.7519.762

Gruber, J., Hendren, N., \& Townsend, R. M. (2014). The Great Equalizer: Health Care Access and Infant Mortality in Thailand. American Economic Journal: Applied Economics, 6(1), 91-107. https://doi.org/10.1257/app.6.1.91

Hangoma, P., Robberstad, B., \& Aakvik, A. (2018). Does Free Public Health Care Increase Utilization and Reduce Spending? Heterogeneity and Long-Term Effects. World Development, 101, 334-350. https://doi.org/10.1016/j.worlddev.2017.05.040

Heckman, J., Ichimura, H., Smith, J., \& Todd, P. (1998). Characterizing Selection Bias Using Experimental Data. Econometrica, 66(5), 1017-1098. https://doi.org/10.2307/2999630

Heckman, J., Ichimura, H., \& Todd, P. (1997). Matching as an Econometric Evaluation Estimator: Evidence from Evaluating a Job Training Programme. The Review of Economic Studies, 64(4), 605-654. https://doi.org/10.2307/2971733

Jütting, J. P. (2004). Do Community-based Health Insurance Schemes Improve Poor People's Access to Health Care? Evidence from Rural Senegal. World Development, 32(2), 273-288. https://doi.org/10.1016/j.worlddev.2003.10.001

Lee, Y. C., Huang, Y. T., Tsai, Y. W., Huang, S. M., Kuo, K. N., McKee, M., \& Nolte, E. (2010). The impact of universal National Health Insurance on population health: the experience of Taiwan. BMC Health Services Research, 10(1), 225. https://doi.org/10.1186/1472-6963-10-225

Lei, X., \& Lin, W. (2009). The New Cooperative Medical Scheme in rural China: does more coverage mean more service and better health?Health Economics, 18(S2), S25-S46. https://doi.org/10.1002/hec.1501

Levy, H., \& Meltzer, D. (2001). What do we really know about whether health insurance affects health? Ann Arbor, MI: University of Michigan, Economic Research Initiative on the Uninsured, Working Paper 6.

Mate, K. S., Sifrim, Z. K., Chalkidou, K., Cluzeau, F., Cutler, D., Kimball, M., ... \& Barker, P. (2013). Improving health system quality in low-and middle-income countries that are expanding health 
coverage: a framework for insurance. International Journal for Quality in Health Care, 25(5), 497504. https://doi.org/10.1093/intqhc/mzt053

Mensah, J., Oppong, J. R., \& Schmidt, C. M. (2010). Ghana's National Health Insurance Scheme in the context of the health MDGs: An empirical evaluation using propensity score matching. Health Economics, 19(S1), 95-106. https://doi.org/10.1002/hec.1633

Miller, G., Pinto, D. M., \& Vera-Hernández, M. (2009). High-powered incentives in developing country health insurance: evidence from Colombia's regimen subsidiado. NBER Working Paper 15456.

Ministry of Health. (2004). National Health Insurance Policy Framework for Ghana (Revised Version). Accra, Ghana.

[dataset] Multiple Indicator Cluster Survey, Ghana, Wave 4. (2011), available at http://mics.unicef.org/surveys

National Health Insurance Authority. (2010). Annual Report 2010, Accra, Ghana.

Nguyen, H. T., Rajkotia, Y., \& Wang, H. (2011). The financial protection effect of Ghana National Health Insurance Scheme: evidence from a study in two rural districts. International Journal for Equity in Health, 10(4), 1-12. https://doi.org/10.1186/1475-9276-10-4

Nyman, J. A. (1999). The value of health insurance: the access motive. Journal of Health Economics, 18(2), 141-152. https://doi.org/10.1016/S0167-6296(98)00049-6

Okoroh, J., Essoun, S., Seddoh, A., Harris, H., Weissman, J. S., Dsane-Selby, L., \& Riviello, R. (2018). Evaluating the impact of the national health insurance scheme of Ghana on out of pocket expenditures: a systematic review. BMC Health Services Research, 18(1), 426. https://doi.org/10.1186/s12913-018-3249-9

Owusu-Sekyere, E. \& Chiaraah, A. (2014). Demand for Health Insurance in Ghana: What Factors Influence Enrollment? American Journal of Public Health Research, 2(1), 27-35. https://doi.org/10.12691/ajphr-2-1-6

Pfutze, T. (2014). The effects of Mexico's Seguro Popular Health Insurance on Infant Mortality: An Estimation with Selection on the Outcome Variable. World Development, 59, 475-486. https://doi.org/10.1016/j.worlddev.2014.02.008

Powell-Jackson, T., Hanson, K., Whitty, C. J., \& Ansah, E. K. (2014). Who benefits from free healthcare? Evidence from a randomized experiment in Ghana. Journal of Development Economics, 107, 305-319. https://doi.org/10.1016/j.jdeveco.2013.11.010 
Quimbo, S. A., Peabody, J. W., Shimkhada, R., Florentino, J., \& Solon, O. (2011). Evidence of a causal link between health outcomes, insurance coverage, and a policy to expand access: experimental data from children in the Philippines. Health Economics, 20(5), 620-630. https://doi.org/10.1002/hec.1621

Ridde, V., \& Morestin, F. (2011). A scoping review of the literature on the abolition of user fees in health care services in Africa. Health policy and planning,26(1), 1-11. https://doi.org/10.1093/heapol/czq021

Rosenbaum, P. R. (2002). Observational Studies. Springer, New York.

Rosenbaum, P. R., \& Rubin, D. B. (1983). The central role of the propensity score in observational studies for causal effects. Biometrika, 70(1), 41-55. https://doi.org/10.1093/biomet/70.1.41

Rowe, A. K., de Savigny, D., Lanata, C. F., \& Victora, C. G. (2005). How can we achieve and maintain high-quality performance of health workers in low-resource settings? Lancet, 366, 10261035. https://doi.org/10.1016/S0140-6736(05)67028-6

Rubin, D. B. (2001). Using propensity scores to help design observational studies: application to the tobacco litigation. Health Services and Outcomes Research Methodology, 2(3-4), 169-188.

Sianesi, B. (2004). An evaluation of the Swedish system of active labor market programs in the 1990s. Review of Economics and $\quad$ Statistics, 86(1), https://doi.org/10.1162/003465304323023723

Singh, K., Osei-Akoto, I., Otchere, F., Sodzi-Tettey, S., Barrington, C., Huang, C., ... \& Speizer, I. (2015). Ghana's National Health insurance scheme and maternal and child health: a mixed methods study. BMC Health Services Research, 15(1), 108. https://doi.org/10.1186/s12913-015-0762$\mathrm{y}$

Smith, J. A., \& Todd, P. E. (2005). Does matching overcome LaLonde's critique of nonexperimental estimators? Journal of Econometrics, 125(1-2), 305-353. https://doi.org/10.1016/j.jeconom.2004.04.011

Spaan, E., Mathijssen, J., Tromp, N., McBain, F., Have, A. T., \& Baltussen, R. (2012). The impact of health insurance in Africa and Asia: a systematic review. Bulletin of the World Health Organization, 90, 685-692. https://doi.org/10.2471/BLT.12.102301

Strupat, C., \& Klohn, F. (2018). Crowding out of solidarity? Public health insurance versus informal transfer networks in Ghana. World Development, 104, 212-221. https://doi.org/10.1016/j.worlddev.2017.11.004 
Trujillo, A. J., Portillo, J. E., \& Vernon, J. A. (2005). The Impact of Subsidized Health Insurance for the Poor: Evaluating the Colombian Experience Using Propensity Score Matching. International Journal of Health Care Finance and Economics, 5(3), 211-239. https://doi.org/10.1007/s10754-005-1792-5

Wagstaff, A. (2007). Health Insurance for the Poor: Initial Impacts of Vietnam's Health Care Fund for the Poor. World Bank Impact Evaluation Series No. 11, Policy Research Working Paper No. WPS4134.

Witter, S., Adjei, S., Armar-Klemesu, M., \& Graham, W. (2009). Providing free maternal health care: ten lessons from an evaluation of the national delivery exemption policy in Ghana. Global Health Action, 2(1), 1881. https://doi.org/10.3402/gha.v2i0.1881

World Health Organization. (2010). World Health Report, 2010: Health systems financing, the path to universal coverage. World Health Organization: Geneva.

World Health Organization. (2011). Haemoglobin concentrations for the diagnosis of anaemia and assessment of severity. (No. WHO/NMH/NHD/MNM/11.1). World Health Organization.

Xu, K., Evans, D. B., Kadama, P., Nabyonga, J., Ogwal, P. O., Nabukhonzo, P., \& Aguilar, A. M. (2006). Understanding the impact of eliminating user fees: Utilization and catastrophic health expenditures in Uganda. Social science \& medicine, 62(4), 866-876. https://doi.org/10.1016/j.socscimed.2005.07.004

Yates, R. (2009). Universal health care and the removal of user fees. Lancet, 373, 2078-2081. https://doi.org/10.1016/S0140-6736(09)60258-0 


\section{Appendix}

\section{A. Balancing tests}

The percentage bias, or standardized difference, being calculated for each variable before and after matching for each method can assess which method minimizes the bias

between the two groups and by how much. It is computed as \% bias $=\frac{\left(\bar{x}_{t}-\bar{x}_{c}\right)}{\sqrt{\frac{\left(s_{t}^{2}-s_{c}^{2}\right)}{2}}}$ for continuous variables and as $\%$ bias $=\frac{\hat{p}_{t}-\hat{p}_{c}}{\sqrt{\frac{\left(\hat{p}_{t}\left(1-\hat{p}_{t}\right)+\hat{p}_{\left.c\left(1-\hat{p}_{c}\right)\right)}\right.}{2}}}$ for dichotomous variables where $\bar{x}_{t}, \bar{x}_{c}$ and $s_{t}^{2}, s_{c}^{2}$ are respectively the sample means and the sample variance of the two groups and $\hat{p}_{t}$ and $\hat{p}_{c}$ represent the mean of the dichotomous variables in the treatment and control group, respectively. It represents the difference between the mean of the two samples in units of the pooled standard deviation (Austin, 2009). The Rubin's B is the absolute standardized difference of the means of the linear index of the propensity score in the treated and non-treated group. Rubin (2001) recommends it to be lower than 25 for the samples to be considered as sufficiently balanced. 
Table 9: Balancing tests

\begin{tabular}{|c|c|c|c|c|c|}
\hline & \multicolumn{5}{|c|}{$\%$ Bias } \\
\hline & $\begin{array}{c}\text { Before } \\
\text { matching }\end{array}$ & $\begin{array}{c}\text { NN } \\
\text { w/ repl }\end{array}$ & $\begin{array}{c}\text { NN } \\
\text { w/o repl }\end{array}$ & Radius & Kernel \\
\hline \multicolumn{6}{|l|}{ Child's characteristics } \\
\hline Male & 1.0 & 1.6 & 1.8 & 0.9 & 1.1 \\
\hline Age in days & $41.5 * * *$ & -1.7 & $36.4 * * *$ & -1.0 & -0.8 \\
\hline \multicolumn{6}{|l|}{ Mother's characteristics } \\
\hline \multicolumn{6}{|l|}{ Education } \\
\hline Primary & -3.9 & $-4.6 * *$ & $-5.3 * *$ & -2.0 & -0.4 \\
\hline Middle/JSS & 1.1 & $7.7 * * *$ & 0.7 & $6.9 * * *$ & $6.4 * * *$ \\
\hline Secondary + & $18.1^{* * *}$ & $8.2 * * *$ & $5.1 * *$ & $7.1 * * *$ & $7.5^{* * *}$ \\
\hline \multicolumn{6}{|l|}{ Household head's characteristics } \\
\hline Male & 3.4 & $-4.4 * *$ & $6.1 * *$ & 0.2 & -0.1 \\
\hline \multicolumn{6}{|l|}{ Education } \\
\hline Primary & $-9.1 * * *$ & 0.5 & $-5.8 * *$ & 2.5 & 2.6 \\
\hline Middle/JSS & 1.0 & $4.5^{*}$ & 0.3 & $7.2 * * *$ & $7.2 * * *$ \\
\hline Secondary + & $19.4 * * *$ & $4.9 * *$ & $6.0^{* * *}$ & $6.5 * * *$ & $6.8 * * *$ \\
\hline \multicolumn{6}{|l|}{ Ethnicity } \\
\hline Akan & $-14.3 * * *$ & 1.2 & $-12.7 * * *$ & 1.4 & 0.8 \\
\hline Ga/Dangme & $-10.2 * * *$ & -1.4 & $-8.7 * * *$ & -1.9 & -2.0 \\
\hline Ewe & $-11.1 * * *$ & $6.3 * * *$ & $-9.2 * * *$ & 2.8 & 2.3 \\
\hline Other & -3.3 & $3.8^{*}$ & -1.9 & 2.1 & 1.8 \\
\hline \multicolumn{6}{|l|}{ Religion } \\
\hline Christian & 0.5 & $8.8 * * *$ & -1.7 & $8.1 * * *$ & $7.8 * * *$ \\
\hline Muslim & $11.8 * * *$ & $-5.4 * *$ & $8.8^{* * *}$ & $-4.8^{* *}$ & -3.7 \\
\hline No religion & $-5.3 * *$ & 1.5 & -2.5 & 3.0 & 2.8 \\
\hline \multicolumn{6}{|l|}{ Household's characteristics } \\
\hline Urban & $15.5 * * *$ & $6.3 * * *$ & $5.8 * *$ & $6.3 * * *$ & $8.4 * * *$ \\
\hline \multicolumn{6}{|l|}{ Region } \\
\hline Western & $-9.0 * * *$ & -0.1 & $-6.3 * *$ & -1.6 & -2.3 \\
\hline Central & $-27.0 * * *$ & 2.6 & $-22.4 * * *$ & 2.2 & 2.1 \\
\hline Greater Accra & $-11.9 * * *$ & -1.6 & $-8.9 * * *$ & -1.5 & -1.7 \\
\hline Volta & $-7.1 * * *$ & 0.5 & $-4.7 *$ & 0.0 & -0.5 \\
\hline Eastern & -1.8 & 0.9 & -0.3 & 2.8 & 2.7 \\
\hline Ashanti & $5.7 * *$ & 0.1 & 3.7 & -0.7 & -1.8 \\
\hline Brong Ahafo & $9.9 * * *$ & 2.9 & $4.8 * *$ & 1.5 & 1.6 \\
\hline Northern & $-9.4 * * *$ & -0.2 & $-5.6^{* *}$ & 0.6 & 1.0 \\
\hline Upper East & $22.0 * * *$ & 3.9 & $20.3^{* * *}$ & 2.8 & 2.5 \\
\hline Number of household members & -2.7 & -0.6 & -1.3 & $-5.8 * *$ & $-7.3 * * *$ \\
\hline Number of household children $<5$ years & $-17.2 * * *$ & $5.8 * * *$ & $-12.1 * * *$ & 3.1 & 1.9 \\
\hline Average num. of people sleeping per room & $-20.3 * * *$ & $0.5^{* *}$ & $-16.1 * * *$ & 3.0 & 3.3 \\
\hline Wealth quintile & $18.6^{* * *}$ & $5.6^{* *}$ & 3.0 & $4.4^{*}$ & $6.7 * * *$ \\
\hline Distance to closest health care facility $(\mathrm{km})$ & $-24.5 * * *$ & $-5.0 * *$ & $-16.8 * * *$ & $-5.0 * *$ & $-6.7 * * *$ \\
\hline Distance to closest district capital (km) & $-16.5 * * *$ & -0.5 & $-7.6 * * *$ & 1.5 & 0.4 \\
\hline Average bias & 13.0 & 3.3 & 8.9 & 3.1 & 3.2 \\
\hline$\%$ change due to matching & & $74.62 \%$ & $31.54 \%$ & $76.15 \%$ & $75.38 \%$ \\
\hline Rubin's B & 93.9 & 25.1 & 74.8 & 23.9 & 24.6 \\
\hline
\end{tabular}

${ }^{*} \mathrm{p}<0.10,{ }^{* *} \mathrm{p}<0.05, * * * \mathrm{p}<0.01 ; \mathrm{NN} \mathrm{w} /$ repl: nearest neighbor with replacement; $\mathrm{NN}$ w/o repl: nearest neighbor without replacement 


\section{B. Histogram of the propensity scores}

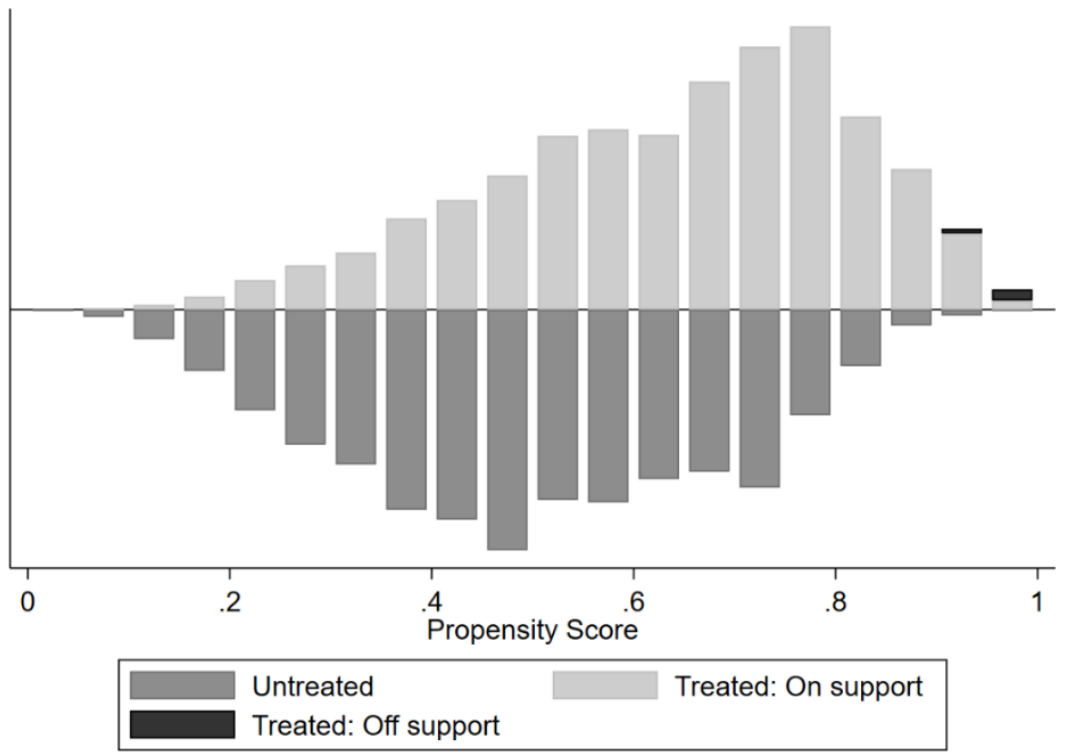

"Treated: On support" indicates the children with health insurance that have a suitable match among children without health insurance ("Untreated"). "Treated: Off support" indicates the children with health insurance that do not have a suitable match.

Figure 5: Propensity score distribution and common support 


\section{Robustness checks - Matching algorithms}

Table 10: Robustness checks - Matching Algorithms

\begin{tabular}{l|l||l|l|l|l}
\hline \multicolumn{9}{c}{ Panel A: Health outcomes } \\
\hline & $\begin{array}{l}\text { Baseline: } \\
\text { Radius [0.01] }\end{array}$ & Kernel & $\begin{array}{l}\text { Nearest } \\
\text { Neighbor }\end{array}$ & $\begin{array}{c}\text { Radius } \\
{[0.005]}\end{array}$ & $\begin{array}{c}\text { Radius } \\
{[0.02]}\end{array}$ \\
\hline Height-for-age z-score & $0.172 * * *$ & $0.172 * * *$ & $0.201 * * *$ & $0.190 * * *$ & $0.168^{* * *}$ \\
& $(0.042)$ & $(0.042)$ & $(0.052)$ & $(0.041)$ & $(0.045)$ \\
Not anemic & $0.103 * * *$ & $0.099 * * *$ & $0.101 * * *$ & $0.106 * * *$ & $0.097 * * *$ \\
& $(0.019)$ & $(0.019)$ & $(0.024)$ & $(0.020)$ & $(0.020)$ \\
\hline
\end{tabular}

Panel B: Health care utilization outcomes

\begin{tabular}{l|l||l|l|l|l}
\hline Use of HCF & $0.338 * * *$ & $0.334 * * *$ & $0.313 * * *$ & $0.341 * * *$ & $0.335 * * *$ \\
& $(0.031)$ & $(0.030)$ & $(0.037)$ & $(0.031)$ & $(0.030)$ \\
$\begin{array}{c}\text { Chose HCF for } \\
\text { treatment }\end{array}$ & $0.228 * * *$ & $0.218 * * *$ & $0.178 * * *$ & $0.216 * * *$ & $0.217 * * *$ \\
& $(0.041)$ & $(0.038)$ & $(0.049)$ & $(0.042)$ & $(0.041)$ \\
\hline
\end{tabular}

$* \mathrm{p}<0.10, * * \mathrm{p}<0.05, * * * \mathrm{p}<0.01$. Average treatment effects on the treated (ATT) computed with different matching algorithms. Nearest neighbor matching is with replacement. Radius matching: caliper in brackets. Values in parentheses are standard errors bootstrapped with 500 replications. 


\section{Results by region}

Table 11: Impact of health insurance on health outcomes - Regional results

\begin{tabular}{|c|c|c|c|c|c|c|c|c|c|c|}
\hline & \multicolumn{3}{|c|}{ Brong } & \multicolumn{3}{|c|}{ Greater } & \multicolumn{3}{|r|}{ Upper } & \multirow{2}{*}{$\begin{array}{c}\text { Upper } \\
\text { East }\end{array}$} \\
\hline & Ashanti & Ahafo & Western & Eastern & Accra & Central & Northern & Volta & West & \\
\hline & $(0.17)$ & $(0.20)$ & $(0.16)$ & $(0.19)$ & $(0.15)$ & $(0.11)$ & $(0.06)$ & $(0.16)$ & $(0.13)$ & $(0.10)$ \\
\hline ATT - Not anemic & 0.091 & -0.062 & 0.079 & 0.034 & 0.053 & $0.113 * *$ & $0.089 * *$ & $0.234 * * *$ & $0.121 * *$ & $0.148 * *$ \\
\hline & $(0.07)$ & $(0.07)$ & $(0.06)$ & $(0.08)$ & $(0.05)$ & $(0.05)$ & $(0.04)$ & $(0.07)$ & $(0.05)$ & $(0.06)$ \\
\hline$[\mathrm{N}]$ & [316] & [282] & [322] & [245] & [310] & [423] & [888] & [330] & [498] & [384] \\
\hline
\end{tabular}

$* \mathrm{p}<0.1, * * \mathrm{p}<0.05, * * * \mathrm{p}<0.01$; Propensity score (PS) matching with the radius algorithm (caliper: 0.01). Values in parenthes es are standard errors bootstrapped with 500 replications and values in brackets are the number of observations in the common support area (N); ATT: mean of the treatment group (with NHIS) - mean of the control group, given the PS. Not anemic: hemoglobin $>100 \mathrm{~g} / \mathrm{l}$; "Average wealth index": average household wealth index within the region; "Public Health: Very Bad": \% of respondents who answered "Very badly" to "How does the government handle improving basic health services?" on a 4-item scale - Data from the Afrobarometer 2012. Regions are ranked on the measure of public health care quality. 


\section{E. Impact of health insurance on health outcomes: heterogeneous effects by wealth}

Table 12: Impact of health insurance on health outcomes - By wealth

\begin{tabular}{|c|c|c|c|c|c|c|c|c|}
\hline \multirow[t]{2}{*}{ Household: } & \multicolumn{4}{|c|}{ Lower income } & \multicolumn{3}{|c|}{ Higher income } & \multirow[b]{2}{*}{ Difference } \\
\hline & Mean C & ATT & $\%$ & $\Gamma$ & Mean C & ATT & $\%$ & \\
\hline $\begin{array}{l}\text { Height-for-age z-score } \\
{[\mathrm{N}]}\end{array}$ & -1.609 & $\begin{array}{l}0.190 * * * \\
(0.05) \\
{[4,694]}\end{array}$ & 11.8 & 1.3 & -1.066 & $\begin{array}{l}0.089 \\
(0.10) \\
{[2,223]}\end{array}$ & 8.3 & $\begin{array}{l}0.101 * * \\
(0.05)\end{array}$ \\
\hline $\begin{array}{l}\text { Not anemic } \\
\qquad \mathrm{N}]\end{array}$ & 0.389 & $\begin{array}{l}0.115 * * * \\
(0.02) \\
{[2,646]}\end{array}$ & 29.6 & 1.3 & 0.739 & $\begin{array}{l}0.023 \\
(0.03) \\
{[1,542]}\end{array}$ & 3.1 & $\begin{array}{l}0.091 * * * \\
(0.02)\end{array}$ \\
\hline
\end{tabular}

$* \mathrm{p}<0.1, * * \mathrm{p}<0.05, * * * \mathrm{p}<0.01$; Propensity score (PS) matching with the radius algorithm (caliper: 0.01$)$. Values in parentheses are standard errors and values in brackets are the number of observations in the common support area (N); Standard errors of the ATTs are bootstrapped with 500 replications; Mean C: after matching mean of control group; ATT: mean of the treatment group (with NHIS) - mean of the control group, given the PS; $\Gamma$ : critical level of hidden bias from Rosenbaum bounds sensitivity analysis $(10 \%$ level), reported only if $\mathrm{p}<0.1$; Lower income: if household wealth index is lower than national median. Not anemic: hemoglobin $\geq 100 \mathrm{~g} / \mathrm{l}$. 
Table 13: Robustness checks - varying wealth cutoffs

\begin{tabular}{|c|c|c|c|c|c|c|c|c|}
\hline \multirow{3}{*}{ Household: } & \multicolumn{8}{|c|}{ Panel A: Wealth cutoff at $\mathbf{4 0 \%}$} \\
\hline & \multicolumn{4}{|c|}{ Lower income } & \multicolumn{3}{|c|}{ Higher income } & \multirow[b]{2}{*}{ Difference } \\
\hline & Mean C & ATT & $\%$ & $\Gamma$ & Mean C & ATT & $\%$ & \\
\hline $\begin{array}{l}\text { Height-for-age z-score } \\
\qquad \mathrm{N}]\end{array}$ & -1.617 & $\begin{array}{l}0.197 * * * \\
(0.04) \\
{[4,665]}\end{array}$ & 12.2 & 1.3 & -1.066 & $\begin{array}{l}0.087 \\
(0.11) \\
{[2,252]}\end{array}$ & 8.2 & $\begin{array}{l}0.109 * * \\
(0.05)\end{array}$ \\
\hline $\begin{array}{c}\text { Not anemic } \\
\qquad \mathrm{N}]\end{array}$ & 0.388 & $\begin{array}{l}0.115^{* * *} \\
(0.02) \\
{[2,633]}\end{array}$ & 29.6 & 1.25 & 0.735 & $\begin{array}{l}0.028 \\
(0.03) \\
{[1,556]}\end{array}$ & 3.8 & $\begin{array}{l}0.088 * * * \\
(0.02)\end{array}$ \\
\hline
\end{tabular}

\begin{tabular}{|c|c|c|c|c|c|c|c|c|}
\hline \multirow{3}{*}{ Household: } & \multicolumn{8}{|c|}{ Panel B: Wealth cutoff at $60 \%$} \\
\hline & \multicolumn{4}{|c|}{ Lower income } & \multicolumn{3}{|c|}{ Higher income } & \multirow[b]{2}{*}{ Difference } \\
\hline & Mean C & ATT & $\%$ & $\Gamma$ & Mean C & ATT & $\%$ & \\
\hline $\begin{array}{l}\text { Height-for-age z-score } \\
\qquad[\mathrm{N}]\end{array}$ & -1.578 & $\begin{array}{l}0.190 * * * \\
(0.04) \\
{[5,601]}\end{array}$ & 12.0 & 1.3 & -0.860 & $\begin{array}{l}0.036 \\
(0.11) \\
{[1,260]}\end{array}$ & 4.2 & $\begin{array}{l}0.154 * * * \\
(0.05)\end{array}$ \\
\hline $\begin{array}{l}\text { Not anemic } \\
\qquad[\mathrm{N}]\end{array}$ & 0.417 & $\begin{array}{l}0.122 * * * \\
(0.02) \\
{[3,239]}\end{array}$ & 29.3 & 1.3 & 0.826 & $\begin{array}{l}-0.010 \\
(0.03) \\
{[876]}\end{array}$ & 1.2 & $\begin{array}{l}0.132 * * * \\
(0.02)\end{array}$ \\
\hline
\end{tabular}

$* \mathrm{p}<0.1, * * \mathrm{p}<0.05, * * * \mathrm{p}<0.01$; Propensity score (PS) matching with the radius algorithm (caliper: 0.01 ). Values in parentheses are standard errors and values in brackets are the number of observations in the common support area $(\mathrm{N})$; Standard errors of the ATTs are bootstrapped with 500 replications; Mean C: after matching mean of control group; ATT: mean of the treatment group (with NHIS) - mean of the control group, given the PS; Not anemic: hemoglobin $\geq$ $100 \mathrm{~g} / \mathrm{l}$. Panel A compares children in the bottom two wealth quintiles (lower income) to children in the upper three quintiles (higher income). Panel B compares children in the bottom three wealth quintiles (lower income) to children in the upper two quintiles (higher income). 


\section{F. Impact of health insurance on health outcomes: heterogeneous effects by health care quality}

Table 14: Impact of health insurance on health outcomes - By health care quality

\begin{tabular}{|c|c|c|c|c|c|c|c|c|c|}
\hline \multirow{2}{*}{ Household: } & \multicolumn{4}{|c|}{ High quality } & \multicolumn{4}{|c|}{ Low quality } & \multirow[b]{2}{*}{ Difference } \\
\hline & Mean C & ATT & $\%$ & $\Gamma$ & Mean C & ATT & $\%$ & $\Gamma$ & \\
\hline $\begin{array}{l}\text { Height-for-age z-score } \\
\qquad[\mathrm{N}]\end{array}$ & -1.535 & $\begin{array}{l}0.185 * * * \\
(0.05) \\
{[5,150]}\end{array}$ & 12.1 & 1.3 & -1.172 & $\begin{array}{l}0.169^{*} \\
(0.09) \\
{[1,752]}\end{array}$ & 14.4 & 1.2 & $\begin{array}{l}0.016 \\
(0.05)\end{array}$ \\
\hline $\begin{array}{l}\text { Not anemic } \\
\qquad[\mathrm{N}]\end{array}$ & 0.404 & $\begin{array}{l}0.118 * * * \\
(0.02) \\
{[2,627]}\end{array}$ & 29.2 & 1.4 & 0.707 & $\begin{array}{l}0.046^{*} \\
(0.03) \\
{[1,553]}\end{array}$ & 6.5 & 1.35 & $\begin{array}{l}0.072 * * * \\
(0.02)\end{array}$ \\
\hline
\end{tabular}

$* \mathrm{p}<0.1, * * \mathrm{p}<0.05, * * * \mathrm{p}<0.01$. Propensity score matching with radius of caliper 0.01 ; Values in parentheses are standard errors and values in brackets are the number of observations in the common support area $(\mathrm{N})$; Standard errors of the ATTs are bootstrapped with 500 replications; Mean C: after matching mean of control group; ATT: mean of the treatment group (with NHIS) - mean of the control group, given the propensity score; $\Gamma$ : critical level of hidden bias from Rosenbaum bounds sensitivity analysis (10\% level), reported only if $\mathrm{p}<0.1$; Quality: Data from the Afrobarometer: by region, share of respondents who answered very badly to the question "How does the government handles improving basic health services?" on a 4-item scale. High quality regions: five regions with lower share of respondents who said very badly, i.e. Northern, Upper East, Upper West, Volta and Central regions; Not anemic: hemoglobin $\geq 100 \mathrm{~g} / \mathrm{l}$.

\section{G. Robustness check: impact of health insurance on health outcomes: heterogeneous effects by insurance coverage}

Table 15: Impact of health insurance on health outcomes - By NHIS coverage within the region

\begin{tabular}{|c|c|c|c|c|c|c|c|c|c|}
\hline \multirow[t]{2}{*}{ Household: } & \multicolumn{4}{|c|}{ Low NHIS coverage } & \multicolumn{4}{|c|}{ High NHIS coverage } & \multirow[b]{2}{*}{ Difference } \\
\hline & Mean C & ATT & $\%$ & $\Gamma$ & Mean C & ATT & $\%$ & $\Gamma$ & \\
\hline $\begin{array}{l}\text { Height-for-age z-score } \\
\qquad[\mathrm{N}]\end{array}$ & -1.512 & $\begin{array}{c}0.207 * * * \\
(0.05) \\
{[3,904]}\end{array}$ & 13.7 & 1.35 & -1.362 & $\begin{array}{l}0.141 * * \\
(0.07) \\
{[2,995]}\end{array}$ & 10.4 & 1.15 & $\begin{array}{c}0.066 \\
(0.04)\end{array}$ \\
\hline $\begin{array}{l}\text { Not anemic } \\
\qquad[\mathrm{N}]\end{array}$ & 0.535 & $\begin{array}{c}0.098 * * * \\
(0.02) \\
{[2,302]}\end{array}$ & 18.3 & 1.45 & 0.477 & $\begin{array}{l}0.109 * * * \\
(0.03) \\
{[1,862]}\end{array}$ & 22.9 & 1.3 & $\begin{array}{l}-0.011 \\
(0.02)\end{array}$ \\
\hline
\end{tabular}

$* \mathrm{p}<0.1, * * \mathrm{p}<0.05, * * * \mathrm{p}<0.01$. Propensity score matching with radius of caliper 0.01 ; Values in parentheses are standard errors and values in brackets are the number of observations in the common support area $(\mathrm{N})$; Standard errors of the ATTs are bootstrapped with 500 replications; Mean C: after matching mean of control group; ATT: mean of the treatment group (with NHIS) - mean of the control group, given the propensity score; $\Gamma$ : critical level of hidden bias from Rosenbaum bounds sensitivity analysis ( $10 \%$ level), reported only if $\mathrm{p}<0.1$; Low NHIS coverage: five regions with lower share of NHIS membership among children under five years old, i.e. Central, Greater Accra, Western, Volta and Brong Ahafo regions; Not anemic: hemoglobin $\geq 100 \mathrm{~g} / \mathrm{l}$. 


\section{H. Impact of health insurance on health outcomes: heterogeneous effects by wealth and health}

\section{care quality}

Table 16: Impact of health insurance on health outcomes - By wealth and health care quality

\begin{tabular}{|c|c|c|c|c|c|c|c|c|c|c|c|c|}
\hline \multirow{3}{*}{$\begin{array}{l}\text { Region } \\
\text { Household } \\
\end{array}$} & \multicolumn{6}{|c|}{ High quality } & \multicolumn{6}{|c|}{ Low quality } \\
\hline & \multicolumn{3}{|c|}{ Lower income } & \multicolumn{3}{|c|}{ Higher income } & \multicolumn{3}{|c|}{ Lower income } & \multicolumn{3}{|c|}{ Higher income } \\
\hline & Mean C & ATT & $\Gamma$ & Mean C & ATT & $\%$ & Mean C & ATT & $\%$ & Mean C & ATT & $\%$ \\
\hline $\begin{array}{l}\text { Height-for-age z-score } \\
{[\mathrm{N}]}\end{array}$ & -1.647 & $\begin{array}{l}0.193 * * * \\
(0.05) \\
{[3,972]}\end{array}$ & 11.71 .3 & -1.134 & $\begin{array}{l}0.073 \\
(0.11) \\
{[1,150]}\end{array}$ & 6.4 & $\mid-1.397$ & $\begin{array}{l}0.220 * \\
(0.11) \\
{[719]}\end{array}$ & $\begin{array}{ll}15.7 & 1.2 \\
\end{array}$ & -1.088 & $\begin{array}{l}0.179 \\
(0.13) \\
{[1,024}\end{array}$ & 16.5 \\
\hline $\begin{array}{l}\text { Not anemic } \\
{[\mathrm{N}]}\end{array}$ & 0.341 & $\begin{array}{l}0.132 * * * \\
(0.03) \\
{[2,005]}\end{array}$ & 38.71 .4 & 0.660 & $\begin{array}{l}0.006 \\
(0.05) \\
{[571]}\end{array}$ & 0.8 & $\mid 0.564$ & $\begin{array}{l}0.058 \\
(0.04) \\
{[636]}\end{array}$ & 10.3 & 0.782 & $\begin{array}{l}0.043 \\
(0.03) \\
{[909]}\end{array}$ & 5.5 \\
\hline
\end{tabular}

$* \mathrm{p}<0.1,{ }^{*} \mathrm{p}<0.05, * * * \mathrm{p}<0.01$. Propensity score matching with radius of caliper 0.01 ; Values in parentheses are standard errors bootstrapped with 500 replications and values in brackets are the number of observations in the common support area (N); Mean C: after matching mean of control group; ATT: mean of the treatment group (with NHIS) - mean of the control group, given the propensity score; $\Gamma$ : critical level of hidden bias from Rosenbaum bounds sensitivity analysis (10\% level), reported only if $\mathrm{p}<0.1$; Quality: Data from the Afrobarometer: by region, share of respondents who answered very badly to the question "How does the government handles improving basic health services?" on a 4-item scale. High quality regions: five regions with lower share of respondents who said very badly, i.e. Northern, Upper East, Upper West, Volta and Central regions; Lower income: if household wealth index is lower than the national median. Not anemic: hemoglobin $\geq 100 \mathrm{~g} / \mathrm{l}$. 